\title{
ESTUDIO DE LA SEXTA EDICIÓN DEL DICCIONARIO DE LA LENGUA CASTELLANA DE LA REAL ACADEMIA ESPAÑOLA*
}

\section{STUDY OF THE SIXTH EDITION OF THE DICCIONARIO DE LA LENGUA CASTELLANA BY THE REAL ACADEMIA ESPAÑOLA}

\author{
NATALia Terrón \\ Universitat Autònoma de Barcelona \\ Natalia.Terron@uab.cat \\ JOAN TORRUELLA \\ ICREA - Universitat Autònoma de Barcelona \\ Joan.Torruella@uab.cat
}

Recibido: 05/12/2018

Aceptado: 14/02/2019

\section{Resumen}

La sexta edición del Diccionario de la lengua castellana de la Real Academia Española se publicó en 1822, solamente cinco años después de la inmediatamente anterior con la urgencia de resolver la falta en el mercado de ejemplares. La revisión del repertorio está marcada por un afán economizador tanto por lo que respecta a la supresión de lemas - como se indica en el Prólogo (1822), de aquellos que no se ajustan a las normas de pronunciación y ortografía o que han quedado anticuados - como al acortamiento de definiciones. En la revisión del enunciado definicional se mantienen los mismos criterios acordados para la edición precedente, lo que de-

\begin{abstract}
The sixth edition of the Diccionario de la lengua castellana by the Real Academia Espanola was published in 1822 . That was only five years after the immediately previous edition to be able to urgently resolve the problem caused by the lack of copies in the market. The revision of the repertoire is marked by an economizing eagerness reflected on the suppression of those lemmas - as indicated in the prólogo (1822), which wither don't meet pronunciation or spelling rules or have simply become out of style - such as the shortening of definitions. In the revision of the definitional statement the same criteria as the one in the previous edition
\end{abstract}

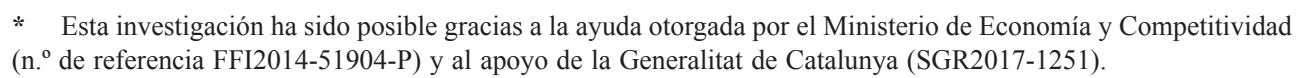

Para citar este artículo / To cite this article: Terrón, Natalia y Torroella, Joan. Estudio de la sexta edición del Diccionario de la lengua castellana de la Real Academia Española.Azorín, Dolores; Clavería, Gloria y Jiménez Ríos, Enrique (Eds.): ELUA: El diccionario de la Academia y su tiempo: lexicografía, lengua y sociedad en la primera mitad del siglo XIX, Anexo V, págs. 109-142.

Enlace/Link: http://dx.doi.org/10.14198/ELUA2019.ANEXO5.06 
muestra la continuidad entre ambas. El aumento, en cambio, es limitado y también presenta una línea continuadora de la edición anterior. Se trata, pues, de una edición más coherente desde el punto de vista de la técnica lexicográfica en la que se lleva a cabo una importante reflexión del tipo de léxico y de la información que debe incluirse en el diccionario.

PALABRAS CLAVE: lexicografía académica, DRAE 1822, siglo XIX. has been held which reflects the continuity in both editions. The increase is limited but also shows a continuance with the previous edition. Therefore we are dealing with a more coherent sample from a lexicographical point of view as there is an important lexical reflection regarding the information that had to be included in this dictionary.

KEYWORDS: academic lexicography, DRAE 1822, nineteenth century.

\section{INTRODUCCIÓN}

La sexta edición del Diccionario de la lengua castellana de la Real Academia Española vio la luz en 1822, solamente cinco años después que su precedente. El prólogo de la obra se inicia justificando la pronta publicación de esta edición, la cual se debe a la falta de ejemplares en el mercado de la anterior:

Como de la escasez de Diccionarios y del anhelo del público, que siempre ha honrado con su aprecio los trabajos de la Academia, dimanase el pronto despacho de los seis mil ejemplares de la quinta edicion, trató inmediatamente de repetirla, y para no hacerla mas embarazosa con el aumento de voces, que tenia reunidas, acordó la supresión de algunas fórmulas y artículos que creyó podrían excusarse sin perjuicio de la claridad conveniente y con mucho ahorro de palabras (DRAE 1822: prólogo).

Posteriormente, se informa de las directrices que han guiado el procedimiento de confección del repertorio. En estas páginas, ya no se señala nada respecto al trabajo en el Diccionario de autoridades, un hecho que distancia esta edición de las publicadas anteriormente. Finalmente, a pesar del breve transcurso de tiempo entre una edición y otra, se anuncian las novedades, basadas en el perfeccionamiento y corrección de la edición anterior más que en el aumento de la nomenclatura. Para la enmienda, se fijan unos objetivos muy claros: la disminución de la obra, tanto a nivel macroestructural, con la supresión de lemas, como microestructural, con el acortamiento de la entrada lexicográfica. Por este motivo, el aumento léxico queda relegado a un segundo plano y se le otorga importancia a las supresiones.

Teniendo en cuenta las directrices acordadas en el prólogo del diccionario, en este estudio se examinan, por un lado, los cambios en la macroestructura respecto a la edición anterior, fundamentalmente las supresiones y adiciones (§ 3.) y, por el otro, las modificaciones en la escritura de las definiciones, una cuestión que ha preocupado a la Academia desde el Diccionario de autoridades (§ 4.).

\section{METODOLOGÍA}

El objetivo fundamental ha consistido, por un lado, en reunir los cambios que afectan a la macroestructura, fundamentalmente, supresiones y adiciones, y, por el otro, en identificar las modificaciones introducidas en la microestructura, especialmente en el enunciado 
definicional. Para ello, se ha llevado a cabo un minucioso cotejo entre la sexta edición del diccionario académico (DRAE 1822) y su edición precedente (DRAE 1817) ${ }^{1}$.

La obtención de las supresiones y adiciones se ha realizado a través de la comparación de la nomenclatura de la sexta edición del diccionario con la de la edición anterior. Para ello, se ha recuperado el lemario de las dos ediciones a través del NTLLE y se ha llevado a cabo la comparación mediante el programa informático COMPADRAE, creado para el proyecto de investigación. Este procedimiento ha permitido reunir las supresiones, el aumento, los cambios gráficos y las erratas de la edición estudiada. Actualmente, la lista de supresiones, adiciones y erratas se puede consultar en línea en la página web del proyecto de investigación: http://draesxix.wixsite.com/draesxix/lemateca.

Para obtener los cambios en la microestructura se han elegido 20 páginas al azar de la edición de 1822 según la técnica de muestreo estratificado, es decir, asegurando que estuviesen presentes en el corpus la mayoría de letras (2 páginas de las letras $A$ y $C$ y 1 página de las letras $B, D, E, F, G, H, I, M, P, R, S, T, V$ y $Z$ ). Posteriormente, se han vuelto a cotejar 10 páginas más como corpus de control (1 página seleccionada al azar de las letras $B, D, F$, $L, M, N, O, P, R$ y $S$ ), las cuales han dado como resultado los mismos tipos de cambios que aparecieron en el primer cotejo. Finalmente, además de estas páginas cotejadas enteramente, siempre que ha sido necesario se han indagado casos determinados con búsquedas dirigidas.

\section{CAMBIOS EN LA MACROESTRUCTURA: SUPRESIONES Y ADICIONES}

\subsection{Supresiones}

Cuando se redactó la sexta edición del diccionario, la Academia atravesaba por unos momentos verdaderamente críticos debido a la falta de capital. A pesar de que el mayor descenso económico, como se ha señalado en las investigaciones de Matilla Tascón (1982: 441) y Fries (1989: 86), tuvo lugar unos años después, en la época de la publicación de la octava y novena edición ${ }^{2}$, a partir de la sexta la corporación se empezó a preocupar por el volumen de la obra debido al coste del papel. El diccionario, por lo tanto, concebido como un producto comercial, debía ser más asequible económicamente tanto para los editores como para los usuarios, hecho que la Academia había tenido presente en 1780 con la reducción del Diccionario de autoridades en un único tomo ( $c f r$. Zamora Vicente 1999: $373)^{3}$. Hasta la sexta edición no se volvió a hacer explícita esta cuestión. En el prólogo de esta edición y, sobre todo, de la siguiente (DRAE 1832) se advierte del objetivo fijado para la revisión: la reducción del volumen de la obra, lo que comporta un descenso en el coste y un progreso en la técnica lexicográfica, ya que la cantidad de voces suprimidas

1 Los datos sobre los que se ha desarrollado el presente estudio se han obtenido y compilado en el marco del proyecto de investigación "Historia interna del Diccionario de la lengua castellana de la Real Academia Española en el siglo XIX (1817-1852)".

2 Como ha apuntado Matilla Tascón (1982: 441), hacia mediados de 1842 la Academia pidió un anticipo para poder afrontar el coste del papel de la novena edición del Diccionario de la lengua castellana.

3 Para simplificar la estructura empleada en el Diccionario de autoridades se llevó a cabo una serie de reestructuraciones entre las que destacan la supresión de las autoridades y la inclusión de un sistema de abreviaturas más conciso e homogéneo ( $c f r$. Seco 1987: 237-258). Además, para poder publicarlo en un único tomo, se imprimió “en folio á tres colunas por llana y cada una con noventa lineas, y con letra pequeña, pero muy clara y limpia" (DRAE 1780: prólogo). 
"hace al Diccionario mas breve y de un uso mas fácil y expedito" (DRAE 1822: prólogo). En el prólogo de la séptima edición se hace referencia a ello:

Ya desde la segunda edicion le redujo á un tomo, para que se puediese adquirir á menos costa, y manejar con mas comodidad, y del mismo modo se ha publicado después, pero sin alteracion notable en esta parte, hasta que en la sexta se suprimieron algunas fórmulas y artículos, de que se dió razon en el prólogo (DRAE 1832: prólogo).

Con la publicación de la sexta edición se inició una importante reestructuración del Diccionario usual que culminó en la edición siguiente (1832), puesto que la revisión del repertorio estuvo marcada por un afán economizador que se refleja, principalmente, en la supresión de lemas, la cual supera notablemente a la adición, un hecho insólito hasta el momento. Como se indicó en el prólogo de 1832, en la parte preliminar de la sexta edición se lleva a cabo una reflexión sobre el léxico que debe incluirse en el diccionario y se ofrece una detallada descripción del tipo de vocablos que se han suprimido de la nomenclatura. En dicho prólogo se llega a la conclusión de que las voces "que eran de un mismo orígen y significado [...] no merecen artículos separados en el Diccionario", ya que solamente "contribuyen a multiplicar [el repertorio]" (DRAE 1822: prólogo).

Ha prestado motivo para la supresion ó reforma de muchos artículos la razon de que los diversos estados de pronunciacion y ortografía que padece una voz desde que sale de una lengua madre, de la latina por ejemplo, hasta que se fija en un idioma vulgar como el castellano, no deben mirarse como palabras diversas, bien se consideren la alteracion que con los tiempo sufren las letras de un mismo órgano, como la $e$ y la $i$, la $o$ y la $u$, la $b$ y la $p$, la $t$ y la $d$, y así otras, ó la torpe pronunciacion de la gente rústica por el vicio contraído y aun casi peculiar de algunas provincias, ó la corrupcion de los tiempos del mal gusto y de la decadencia de las letras (DRAE 1822: prólogo).

Por lo tanto, las voces que se eliminaron de la nomenclatura eran, principalmente, variantes fónicas, gráficas y morfológicas. La cifra de supresiones en la sexta edición asciende a un total de 2.348 formas, lo que corresponde a 2.323 lemas ${ }^{4}$. De estas 2.348 formas: A) el $81 \%$ son voces en desuso ${ }^{5}$ y B) el $19 \%$ se corresponden a palabras que estaban en uso en el momento de la supresión.

A) El porcentaje tan elevado del primer grupo refleja un cambio de pensamiento respecto a las ediciones anteriores, puesto que hasta la cuarta existía un interés por recoger en el diccionario palabras arcaizantes. En el estudio de Jiménez Ríos (2001), dedicado a los arcaísmos en el diccionario de la Academia, se da cuenta de la importancia que este tipo de léxico ha cobrado desde el Diccionario de autoridades. En opinión de este autor, la presencia de voces antiguas en la obra lexicográfica justifica que la elaboración del repertorio haya estado guiada por el criterio del uso, "pues desde siempre tuvo una

4 Un número bastante elevado respecto a la edición anterior de 1817: 838 formas, pero menor que la edición posterior de 1832: 6.399. No obstante, el tipo de supresión en 1832 es distinto del de 1817 y 1822 , ya que en la séptima edición aproximadamente el $80 \%$ de las supresiones corresponden a participios pasivos (cfr. Jiménez Ríos 2018).

5 En esta cifra se incluyen también los participios de pasado que no llevan marca ant. pero que el infinitivo y el participio activo, en caso de existir, sí la llevan. Muchos participios de pasado no aparecen con ninguna marca, ya que esta información se encuentra en el infinitivo. 
especial tendencia a incluir palabras que ya estaban anticuadas en el mismo momento de su incorporación" (Jiménez Ríos 2001: 48). Incluso en el prólogo de la segunda edición del Diccionario de autoridades se hace explícito el deseo de incluir voces arcaicas. Por ello, en las cuatro primeras ediciones del Diccionario usual hasta la publicada en 1803 se produjo un importante incremento de este tipo de léxico. A partir de la quinta edición (1817) y, en especial, en la sexta (1822) y la séptima (1832) se produce un cambio a favor de la supresión de voces antiguas, muchas de las cuales habían sido introducidas en $1803^{6}$ ( $c f r$. Jiménez Ríos 2018). En la sexta edición del diccionario tiene lugar el mayor número de supresiones de voces arcaicas.

De las 2.348 formas antiguas suprimidas, 1.635 no se vuelven a incorporar en ninguna edición posterior. Se trata, principalmente, de variantes fónicas y gráficas que "el uso antiguo las hacia mas ásperas y desabridas" (DRAE 1822: prólogo). Por ello, la información que suele aparecer en la definición de estas voces es el reenvío a la voz moderna, puesto que como se había indicado en el prólogo de la obra "solo la remision de una voz á otra, que está definida, basta para indicar que esta es la mas propia y de un uso mas comun y constante" (DRAE 1822: prólogo).

Respecto al tipo de variantes que se suprimen, en el prólogo se había hecho una descripción de casos particulares que se tenían que eliminar del diccionario. Entre ellos se señalaban, por ejemplo, las voces con alteraciones en fonemas de un mismo órgano articulatorio: $e-i$ (servienta, restreñir, requirir, ringlon), $o-u$ (pulicía, ruciar, ordidura, trojillano, $), d-t$ (salut, probedat, merindat), $g-c$ (sagramento, presigo), etc.; vocablos provinciales (porto, ajadon, roba); palabras "acabadas en $l$ ó en $z$ que antes tuvieron $e$ en su final" (verisímile, inútile, inhábile); voces que "concluían en de á quienes el uso ha quitado después la $e$ final" (honestade meatade); palabras que "principian en $f$ por depravado uso [...] y las que por traer en su orígen latino la $f$ se usaron alguna vez, especialmente los poetas, y han quedado anticuadas" (fuerta, fuella, formiga, fongo); variantes de grupos consonánticos cultos y, especialmente, verbos con sc (tractado, repto, renascer, perficion, merescer, juncto); términos con doble $n$ que se corresponde a ñ (sennero, pennola, estranno) y vocablos con alteraciones entre $r$ y $l$ (tiniebra, temprar, resolubre, prata, periglo). Cabe destacar que, a pesar de que en la quinta edición ya se empieza a despojar el diccionario de léxico arcaico, 39 de estas variantes suprimidas se habían incorporado en el diccionario en la edición anterior de 1817. Este hecho induce a pensar que en la quinta edición todavía existe un interés por recoger voces antiguas.

También se eliminan, siguiendo las directrices del prólogo, diversas formas del sufijo -mente, las cuales tuvieron "un uso vario y vacilante hasta que se ha fijado su terminacion" (DRAE 1822: prólogo). No obstante, las cifras no son muy elevadas: con el sufijo -mient se suprimen 2 voces, con -ment se eliminan 8 , con -mientre 11, con -mentre 4 y con -miente 6 . El mayor número se corresponde a 42 formas antiguas con el sufijo -mente.

Finalmente, junto con el infinitivo, marcado como anticuado, se eliminan 348 participios de los cuales 152 no llevan marcación. El uso de la marca en los participios de pasados no era sistemático.

6 De las voces arcaicas suprimidas, 297 se introducen en la primera edición del Diccionario de autoridades (1726-1739), 127 en la segunda edición del Diccionario de autoridades (1770), 416 en la primera edición del Diccionario usual (1780), 53 en la segunda edición (1783), 369 en la tercera edición (1791), 563 en la cuarta edición (1803) y 56 en la quinta edición (1817). 
Las 248 formas restantes son supresiones con reincorporación, es decir, vuelven a introducirse en una edición posterior del diccionario, especialmente, como se observa en la tabla 1, en la duodécima (1884) y en la decimoquinta (1925).

\begin{tabular}{|c|c|}
\hline 7. ${ }^{\mathrm{a}}$ ed. $(1832)$ & 6 \\
\hline $8 .{ }^{\mathrm{a}}$ ed. $(1837)$ & 6 \\
\hline 9. ${ }^{\mathrm{a}}$ ed. $(1843)$ & 2 \\
\hline $10 .^{\mathrm{a}}$ ed. $(1852)$ & 8 \\
\hline $11 .^{\mathrm{a}}$ ed. $(1869)$ & $23^{7}$ \\
\hline $12 .^{\mathrm{a}}$ ed. $(1884)$ & $41^{8}$ \\
\hline $13 .^{\mathrm{a}}$ ed. $(1899)$ & 15 \\
\hline $14 .^{\mathrm{a}}$ ed. $(1914)$ & 22 \\
\hline $15 .^{\mathrm{a}}$ ed. $(1925)$ & 93 \\
\hline $16 .^{\mathrm{a}}$ ed. $(1936)$ & 9 \\
\hline $17 .^{\mathrm{a}}$ ed. $(1956)$ & 3 \\
\hline $18 .^{\mathrm{a}}$ ed. $(1970)$ & 16 \\
\hline $19 .^{\mathrm{a}}$ ed. $(1984)$ & 2 \\
\hline 20. ${ }^{\mathrm{a}}$ ed. $(1992)$ & 2 \\
\hline
\end{tabular}

Tabla 1.

B) El segundo grupo, voces en uso sin marca ant., representa un $19 \%$ del total de las supresiones. Por un lado, 195 voces se corresponden a variantes no preferidas por la Academia en cuya definición se remite a otro vocablo de uso más común. Este tipo de supresiones no supone un descenso de significados en el lemario sino de significantes (Clavería 2018: 43).

Una parte de estas variantes son términos relacionados con la historia natural. Se suprimen del diccionario 39 voces que denominan plantas y 13 que designan animales. En 40 de ellas la única información lexicográfica que se encuentra en la definición es el reenvío a otra voz, ya sea estableciendo una relación formal entre el lema y la remisión (alabanco a labanco, asison a sison, bredo a bledo, apazote a pazote, lubina a lobina) o una relación de sinonimia (anagiris a hediondo, semivulpa a zarigüeya, almurejo a gramen, camemila a manzanilla) (cfr. Terrón y Torruella 2019). Cabe destacar que 32 de estos términos habían sido introducidos en 1817, "una de las líneas maestras" del aumento de esta edición, ya

$7 \quad$ En el prólogo de la undécima edición se reflexiona sobre el léxico anticuado en el diccionario. Al respecto, la Academia indica que "desea rehabilitar en el uso la mayor parte de tales voces, arrinconadas más bien por ignorar muchos su existencia, que por ser propiamente anticuadas" (DRAE 1869: prólogo). Posiblemente esta sea la causa por la que a partir de esta edición se empiecen a reincorporar voces anticuadas suprimidas anteriormente.

8 En el prólogo de la duodécima edición se vuelve a hacer referencia a la adición de vocabulario anticuado, que en esta edición se acerca "á sus últimos límites, por haberse ahora adoptado regla más eficaz para evitar que lleve el calificativo de anticuada ninguna voz que no deba llevarle: caso en que, descontadas muy pocas, están cuantas viven con juventud eterna en las obras de ingenios próceres de los siglos XVI y XVII" (DRAE 1884: prólogo). La mayor reincorporación de voces marcadas como antiguas se produce en la decimoquinta edición. 
que, como se ha señalado en Clavería (2018: 44), “en una de las salas se trabajó en este tipo de léxico hasta el final de la corrección".

Por otro lado, se eliminan de la nomenclatura del diccionario voces con marcas diatécnica, diatópica y diastrática. El mayor número de supresiones se corresponde a léxico marcado diatópicamente. En el prólogo de la sexta edición se había señalado que se eliminarían del diccionario los términos "que por viciosa pronunciacion en algunas provincias no merecen adoptarse" (DRAE 1822: prólogo). Por este motivo, se suprimen 40 voces pertenecientes a las zonas geográficas presentes en la tabla 2:

\begin{tabular}{|c|c|l|}
\hline MARCA & FRECUENCIA & \multicolumn{1}{|c|}{ EJEMPLOS } \\
\hline$p$. Ar. & 14 & $\begin{array}{l}\text { sítiada, sancho, rujada, gallon, fejuguez, fejugo, alama, } \\
\text { actitar, actitadero, actitado, acotolar, acortadizo, acapizar- } \\
\text { se y acapizado. }\end{array}$ \\
\hline En algunas partes & 8 & $\begin{array}{l}\text { revidar, revidado } \text {, puya, escupita, ceroyo, alirón, ajunjera } \\
\text { y aguilando. }\end{array}$ \\
\hline$p$. Ast. & 7 & $\begin{array}{l}\text { farnero, emburrion, emburriar, emburriado, calleyo, argu- } \\
\text { mal y arguma. }\end{array}$ \\
\hline$p$. Murc. & 6 & licera, escurina, abarrera, sisca, floña y annojo. \\
\hline$p$. Gal. & 2 & solla y fayado \\
\hline$p$. And. & 1 & parparala \\
\hline$p$. Extr. & 1 & asison \\
\hline$p$. Gran. & 1 & alcandueca \\
\hline
\end{tabular}

Tabla 2.

Como se puede observar en la tabla 2, Aragón es la zona que más destaca en la supresión de voces dialectales, una de las provincias más representadas también en el aumento de las diversas ediciones del diccionario académico ( $c f r$. Alvar Ezquerra 1983: 208). Además de estos 40 vocablos, se eliminan tres más que, a pesar de no llevar una marca diatópica, en la definición se restringe su uso a alguna comunidad en concreto, como en los términos tenaceio, "en las ferrerías de Vizcaya llaman así..." (DRAE 1817: s. v. tenaceio) y abeurrea "Señal ó acotamiento que hacen los naturales de Vizcaya..." (DRAE 1817: s. v. abeurrea), o a algunas provincias en general, como en amimar, "Úsase en algunas provincias" (DRAE 1817: s. v. amimar).

En cuanto al léxico de especialidad, se eliminan de la sexta edición 39 vocablos afines a las áreas temáticas que figuran en la tabla 3:

9 Como se ha señalado anteriormente para los participios arcaicos, los participios que aparecen en la tabla 2 (revidado, actitado, acapizado, emburriado) tampoco llevan ninguna marca diatópica, pero su uso restringido a una determinada zona se deduce de la información presente en el infinitivo. 


\begin{tabular}{|c|c|c|}
\hline MARCA & FRECUENCIA & EJEMPLOS \\
\hline Anat. & 7 & $\begin{array}{l}\text { adenología, raninas, sincondrosis, sineurósis, sínfisis, sirascosis, } \\
\text { supraspinato }\end{array}$ \\
\hline Náut. & 5 & abiton, acollador, amantillar, amantillo, estrovito \\
\hline Teól. & 4 & coecual $^{10}$, espiración [2], eviternidad, supositar \\
\hline Cir. & 3 & lujacion, lujarse, parástata \\
\hline Arq. & 2 & acroteria, alquitrabe \\
\hline Astron. & 2 & acronicto, paralaxis \\
\hline for. & 2 & actitadero, actitar \\
\hline Med. & 2 & sorbicion, diacatalicon \\
\hline Ret. & 2 & anominacion, subjecion \\
\hline Agr. & 1 & aurragado \\
\hline Arit. & 1 & equimultíplices \\
\hline Astrol. & 1 & plático \\
\hline Cant. & 1 & dobela \\
\hline Com. & 1 & serpenticida \\
\hline Escol. & 1 & tendente \\
\hline Farm. & 1 & antispodio \\
\hline Gram. & 1 & ablativo absoluto \\
\hline $\begin{array}{l}\text { Hist. Nat., } \\
\text { Mat., Quim. }\end{array}$ & 1 & afine $e^{11}$ \\
\hline Lóg. & 1 & exceptivo \\
\hline
\end{tabular}

Tabla 3 .

El campo temático que sufre más supresiones es el relacionado con el área de la medicina, representado por las marcas Anat. (anatomía), Cir. (cirugía), Farm. (farmacia) y Med. (medicina).

Asimismo, también se eliminan del diccionario 14 voces portadoras de alguna marca diastrática.

\begin{tabular}{|c|c|l|}
\hline MARCA & FRECUENCIA & \multicolumn{1}{c|}{ EJEMPLOS } \\
\hline fam. & 8 & $\begin{array}{l}\text { acabóse, corricorriendo, estirijon, mamaluco, quillotro, } \\
\text { rufalandaina, suegrecita y acapizarse. }\end{array}$ \\
\hline Poét. & 4 & fornaz, fulgecer ideo y penatigero. \\
\hline Germ. & 2 & estravo y galar \\
\hline
\end{tabular}

Tabla 4.

10 La relación a la teología en el término coecual se encuentra en la definición, puesto que se inicia del siguiente modo: "En la teología se usa..." (DRAE 1817: s. v. coecual)

11 En la definición de la voz afine aparecen tres marcas distintas: His. Nat., Mat. y Quim. No obstante, solamente se ha contado una vez 
En la voz parcemiqui la información diastrática aparece en la definición, ya que se señala que se usa "en el estilo festivo" (DRAE 1817: s. v. parcemiqui). El número de voces suprimidas pertenecientes a un determinado estilo es muy reducido respecto al aumento, lo que induce a pensar el valor que se le ha otorgado a este tipo de léxico en el diccionario con el objetivo de reflejar los distintos registros de la época.

Finalmente, aunque no supone un número muy elevado, también se suprimen de la sexta edición 39 participios $^{12}, 22$ diminutivos, 5 formas verbales irregulares, 5 verbos pronominales cuyo significado se incluye en la entrada correspondiente a la forma activa o neutra del verbo y 3 aumentativos. Respecto a los tiempos irregulares de los verbos, cabe destacar que en las Reglas para la corrección de la primera edición del Diccionario de autoridades publicadas en 1757 se había tomado la decisión de incluirlos en la obra lexicográfica con la finalidad de "facilitar su inteligencia á los Estrangeros". No obstante, para poder reducir a un único tomo el Diccionario de autoridades se decidió eliminar estas formas del repertorio. Por ello, la supresión de los 5 tiempos verbales (dame, atrajo, atrajese, atrajera y andudo) deberían considerarse como restos del Diccionario de autoridades que todavía se mantenían en la nomenclatura.

\subsection{Adiciones}

Por lo que respecta al aumento del lemario de la sexta edición, lo primero que destaca es la reducida ampliación de entradas en comparación con el número de supresiones de esta misma edición y en comparación con las de la edición precedente ( $c f r$. Clavería 2018: 40). El volumen de adiciones asciende a un total de 483 formas correspondientes a 424 lemas ${ }^{13}$, 92 de los cuales aparecen en el suplemento. Por lo tanto, la reforma que se pretendía llevar a cabo en esta edición no se centraba en el aumento léxico, como se hizo, por ejemplo, en la cuarta edición del diccionario (DRAE 1803) sino, más bien, en la enmienda de la edición precedente, hecho que se reafirma también debido al corto lapso de tiempo que separa la publicación de ambas, solamente cinco años.

De estas 488 formas incorporadas, 12 son reintroducciones, es decir, ya habían aparecido en ediciones anteriores a la sexta y, por diversas razones, se habían suprimido como lemas del repertorio lexicográfico (abdomen, acianos, aprontamiento, agüela, albarrana, atauxía, candelabro, cauro, celo, cusculia, hiedra y librito). Uno de los motivos de estas reincorporaciones es la pervivencia en el diccionario de la voz como sublema de otra, como ocurre, por ejemplo, en agüela, que desde la segunda edición del Diccionario de autoridades (1770) hasta la quinta del Diccionario usual (1817) se encuentra en el artículo de agüelo, la.

Asimismo, del total de las voces incluidas, 330 permanecerán en el diccionario hasta la edición de 2014 y el resto, como se puede observar en la tabla 5, se suprimirán en ediciones intermedias ${ }^{14}$, algunas de ellas habiendo tenido una vida muy efímera. En este sentido, destacan, las 37 formas eliminadas en la edición de 1832 y las 73 en la de $1884^{15}$.

12 La supresión sistemática de los participios de pasado no se llevará a cabo hasta la edición posterior (cfr. Carriet 2017)

13 Las 59 formas restantes son palabras nuevas que forman parte de lemas múltiples.

14 En algunos casos se produce una interrupción de la presencia de la voz en alguna o algunas ediciones intermedias, es decir, desaparecen en algunas ediciones y posteriormente vuelven a aparecer.

15 Los vocablos eliminados en la séptima edición se corresponden a participios de pasado (garantido, da; exportado, da; repoblado, da; etc.) y a verbos pronominales (repudrirse, prendarse. producirse, etc.), una de las líneas 


\begin{tabular}{|r|r|}
\hline 1832 & 37 \\
\hline 1837 & 3 \\
\hline 1852 & 3 \\
\hline 1869 & 5 \\
\hline 1884 & 73 \\
\hline 1899 & 3 \\
\hline 1914 & 2 \\
\hline 1936 & 1 \\
\hline 1970 & 5 \\
\hline 1984 & 0 \\
\hline 1992 & 3 \\
\hline 2001 & 10 \\
\hline 2014 & 8 \\
\hline
\end{tabular}

Tabla 5.

En cuanto a la tipología de los vocablos incorporados, se sigue prácticamente con las mismas líneas de aumento que en la edición precedente (cfr. Terrón 2018). Un grupo bastante importante es ampliación no significativa desde el punto de vista léxico, es decir, lo que se denomina en el prólogo, "voces fácilmente formables", fundamentalmente diminutivos, aumentativos, superlativos, participios y adverbios acabados en -mente. En la presente edición se añaden un total de 54 lemas diminutivos (p. ej. redita, pepinillo, pechuguilla), algunos completando la cadena morfológica iniciada en ediciones anteriores, como, por ejemplo, jovencico, ca que se incorpora al lema múltiple jovencillo, lla, to, ta incluido en la cuarta edición, 5 superlativos (p. ej. cariñosísimo, ma, ventajosísimamente, vigorosísimamente), 4 aumentativos (p. ej. farolon ${ }^{16}$, frailote ${ }^{17}$, frescote, ta $^{18}$ ), 23 participios - 20 de pasado (p. ej. besuqueado, da, derraigado, da, saboreado, da) y 2 activos (comitente, suplente) - y 7 adverbios acabados en -mente (p. ej. oficiosamente, perceptiblemente, simoniacamente). La inclusión de estos adverbios se contradice con las directrices del prólogo que abogan por su supresión. Lo mismo ocurre con los participios de pasado, a pesar de que su eliminación del diccionario no se llevará a cabo de manera sistemática hasta la edición de 1832. Asimismo, en la sexta edición en particular, se añaden otros grupos de voces derivadas: 23 sustantivos de acción y efecto (p. ej. desembalage "La acción de desenfardar", seseo, "La acción de sesear", pestañeo "La acción y efecto de recortar"), 18 términos formados con el prefijo re- (p. ej. reconquistar; recomponer; repoblado, da) у 15 con el prefijo des- (p. ej. desembrollar, desenfrailar, despenador, ra). Esta línea de aumento de voces derivadas representa un $34.63 \%$ del total de incorporaciones.

Otro grupo de voces que se incorporan en la $6 .^{\text {a }}$ edición son aquellas portadoras de alguna marca, ya sea diacrónica, diastrática, de transición semántica, diatópica o diatécnica. Resulta

de supresión de esta edición ( $c f r$. Carriet 2017). Por su parte, en la duodécima edición se eliminan de manera sistemática los diminutivos de la obra lexicográfica (jovencico, ca; meloncillo; truhanito, ita; etc.).

16 Solamente en masculino; el femenino se añade en 2001.

17 Con el sufijo -on en las ediciones del Diccionario usual de 1817 a 1869.

18 Con el sufijo -on en el Diccionario de autoridades (1732) y hasta undécima del Diccionario usual. 
contradictoria la inclusión de léxico antiguo si se tiene en cuenta el gran porcentaje de supresiones de arcaísmos que tienen lugar en esta edición. A pesar de que en las supresiones se detecta una fuerte voluntad de eliminar lemas con la marca ant., se incorporan 18 voces arcaicas, en cuya definición se remite al equivalente actual (p. ej. abrotante a arbotante; engenerativo, va a generativo, va; omecillo a homicidio; jongolí a alegría), proceso que precisamente justificaba su eliminación del diccionario ( $c f r$. Jiménez Ríos 2001: 52).

Con respecto a la marcación diastrática, se introducen 22 lemas con la etiqueta fam., (p. ej. barullo; farolear; sacasillas). El objetivo de la incorporación de este tipo de léxico, como ya se ha indicado anteriormente, es el de reflejar los distintos registros de la época. Cabe destacar que, igual que en la edición inmediatamente anterior ( $c f r$. Clavería y Freixas 2015; $c f r$. Azorín 2018), una parte de estas adiciones se refieren a apelativos usados en sentido despectivo (p. ej. catacaldos, cominero, putero). En algunos de estos lemas la restricción a un determinado registro se observa a través de la propia definición de la palabra (p. ej. monises "En sentido vulgar moneda o dinero"). También se añaden dos términos pertenecientes a la germanía (agüela y verruguetar) y uno usado en el registro poético (estro).

Referente a las marcas de transición semántica, se añaden 9 voces portadoras de la marca met. (p. ej. arrocinar, egida, riolada), 6 de ellas en segundas acepciones (p. ej. influjo, musas, reanimar).

Por su parte, el incremento de voces dialectales es bastante reducido, puesto que solamente se añaden 5 términos con alguna marca diatópica: lercha, perteneciente a la provincia de la Mancha; espernible a la provincia de Andalucía; rujiada y rujiar a la provincia de Aragón y, por último, tova con la marca en alguna partes. Los términos rujiada y rujiar se eliminan del repertorio académicos en las ediciones de 1837 y 1843, respectivamente, y se vuelven a introducir en la de 1925, el verbo rujiar acompañado de las marcas Aragón, Murcia y Navarra.

Por último, dentro de las voces pertenecientes a una determinada especialidad, como sucede en otras ediciones del diccionario académico, el mayor número de incorporaciones son los términos de la náutica (6) y los que se refieren al campo de la medicina (Med. $4 \mathrm{y}$ Anat. 4). Como novedad, destacan también las voces pertenecientes al ámbito del comercio (4). El resto, como se puede observar en la tabla siguiente, queda muy repartido entre distintas áreas temáticas.

\begin{tabular}{|l|c|l|}
\hline \multicolumn{1}{|c|}{ MARCA } & FRECUENCIA & \multicolumn{1}{c|}{ EJEMPLOS } \\
\hline Náut. & 6 & laboreo, bordada, branque, cerreta, empuñidura, escobén \\
\hline Anat. & 4 & abdomen, piamadre, pubis, sublingual \\
\hline Com. & 4 & importacion, capitalizar $^{19}$, capitalización, déficit $^{20}$ \\
\hline Med. & 4 & insultarse, tegumento, galbanismo, fisiología $^{2}$ \\
\hline Quim. & 3 & cucúrbita, mineralizar, óxido \\
\hline Astron. & 2 & quintante, paralage \\
\hline Agr. & 1 & despueble \\
\hline
\end{tabular}

19 Lleva la marca Comercio en la segunda acepción.

20 La relación al comercio en las voces capitalización y déficit aparece en la definición: "en el comercio significa..." (DRAE 1822). 


\begin{tabular}{|l|c|l|}
\hline \multicolumn{1}{|c|}{ MARCA } & FRECUENCIA & \\
\hline Arq. & 1 & abrotante, \\
\hline Artill. & 1 & estopin, obús \\
\hline Fís. & 1 & repulsivo, va \\
\hline For. & 1 & cuasicontrato \\
\hline Fort. & 1 & aristas \\
\hline Gram. & 1 & propositivo, va \\
\hline Impr. & 1 & estereotipa \\
\hline Maq. & 1 & proyeccion \\
\hline Mar. & 1 & andanada \\
\hline Mil. & 1 & pasavante \\
\hline Miner. & 1 & laboreo \\
\hline Mús. & 1 & preludiar \\
\hline
\end{tabular}

Tabla 6.

Estas incorporaciones demuestran el interés por parte de la Academia en recoger léxico especializado que haya trascendido al lenguaje común. No obstante, el número de vocablos técnicos que se han incluido en esta edición no es excesivo en comparación con la edición inmediatamente anterior, en la que se recoge un número relevante de tecnicismos (Clavería y Freixas 2015: 1310). Los campos que amplían su vocabulario pertenecen a las áreas tradicionales recogidas desde el Diccionario de autoridades, como la náutica.

Finalmente, aunque no aparecen en la tabla por no llevar marca, también es destacable la incorporación de 20 voces que denominan plantas (p. ej. camedrio, chirimoyo, magarzuela), 5 que designan animales (p. ej. tova, picaposte, picagrega) y 4 minerales (p. ej. aguamari$n a$, pirita). La inclusión de voces pertenecientes a la historia natural es una constante en el diccionario académico.

\section{CAMBIOS EN LA MICROESTRUCTURA: REESCRITURA DE LA DEFINI- CIÓN}

En relación a la microestructura de la obra lexicográfica, la redacción de la definición es una cuestión que ha preocupado a la Academia desde la confección del Diccionario de autoridades, el cual representa, en opinión de Freixas (2010: 45-91; 2018: 139), "el inicio de técnicas modernas para la definición que tienen sus raíces en la emulación y superación de modelos europeos". Esta preocupación se evidencia en las Reglas (1743, 1757, 1764 y 1770) elaboradas con el fin de redactar la segunda edición del Diccionario de autoridades. Como se ha observado en el capítulo de Freixas (2018: 140) dedicado a la definición en la edición de 1817, en ellas aparecen observaciones que contribuyeron a homogeneizar esta parte de la entrada lexicográfica. Así, las primeras ediciones del Diccionario usual (1780, $1783,1791,1803$ y 1817) consolidaron modelos de definición y, en especial, la publicada en 
1817, en la cual se llevó a cabo una revisión en la que destaca, sobre todo, la simplificación de las paráfrasis de significado con la supresión de informaciones complementarias.

En la edición inmediatamente posterior se continúa con la revisión iniciada en 1817, por lo que se sigue con las mismas directrices, las cuales aparecen señaladas en el prólogo de la obra:

Se han aclarado y rectificado muchas definiciones, especialmente en los artículos que pertenecen á ciencias naturales [...].

Se han suprimido tambien muchas palabras y expresiones redundantes, y varias noticias y etimologías que han parecido poco necesarias y oportunas: reforma que aun sería mayor, si la estrechez del tiempo hubiera dado lugar á mas detenido examen (DRAE 1817: prólogo).

En la sexta edición se repiten los objetivos mencionados en la quinta, además de revisar también las definiciones pertenecientes a otras facultades y no solamente las que atañen a las ciencias naturales: "se ha procurado con esmero [...] dar mayor claridad usando de términos comunes á las definiciones de las voces de Historia natural ó de otras facultades" (DRAE 1822: prólogo).

Así, en la sexta edición del diccionario, las modificaciones en la definición de las voces afectan (§ 4.1.) a la redacción de las mismas con el objetivo de hacerlas más comprensibles, (§ 4.2.) a la disminución de las paráfrasis de significado de los lemas mediante la supresión de información adicional y fórmulas redundantes, (§ 4.3.) a cuestiones de norma y estilo y, por último, $(\S 4.4$.) a la corrección de algunos errores presentes en la edición de 1817 .

\subsection{Clarificar la redacción de las definiciones}

Como se ha indicado anteriormente, uno de los objetivos que se planteó la Academia a la hora de emprender esta sexta edición fue el de hacer más clara y comprensible la redacción de las definiciones. De hecho, en la propia información lexicográfica de la voz definición se especifica que esta debe ser una "Exposicion clara, exacta y precisa de la naturaleza de alguna cosa" (DRAE 1822: s. v. definición).

Para conseguir este objetivo, en los cambios que experimentan las definiciones de la sexta edición en relación a las de su edición precedente, se observa que (§ 4.1.1.) unas veces se pretende dar mayor precisión a la redacción añadiendo información o cambiando elementos del contenido de la definición de la edición anterior y, (§ 4.1.2.) otras veces, se reescribe enteramente el enunciado definicional.

\subsubsection{Precisar el contenido de la definición}

El primero de los procedimientos indicados anteriormente para clarificar la redacción de las definiciones consiste en dar mayor precisión al contenido del enunciado definicional, objetivo que se pretende conseguir de tres maneras distintas: (a) introduciendo en una cadena de componentes de la definición un nuevo componente que precisa el alcance del significado, (b) añadiendo al enunciado definicional elementos que ayudan a darle más exactitud, y (c) cambiando una palabra del redactado por otra más precisa o por una explicación de su significado. 
(a) Introducción de un nuevo componente en una cadena de componentes

Para obtener mayor precisión en la paráfrasis de significado de un lema se puede incluir un nuevo componente en una cadena de componentes que ya aparecía en la definición de la edición anterior. Son ejemplos de ello las voces grabado [2], moleta, rueda [2], zarandar, anotar, ansina, [1], natural [9], echar sapos y culebras (s. v. sapo), rueca o ruina [2].

\begin{tabular}{|c|c|}
\hline$D R A E 1817$ & DRAE 1822 \\
\hline $\begin{array}{l}\text { GRABADO [2]. S. m. Arte que enseña a esculpir } \\
\text { figuras, ornatos ó letras en laminas de metal ó } \\
\text { troqueles ó en piedras finas. Llamase [...] se } \\
\text { ejecuta en troqueles de metal ó en piedras finas. }\end{array}$ & $\begin{array}{l}\text { GRABADO [2]. S. m. Arte que enseña a esculpir } \\
\text { figuras, ornatos ó letras en laminas de metal } \\
\text { ó troqueles ó en piedras finas. Llamase [...] } \\
\text { se ejecuta en troqueles de metal, en madera ó } \\
\text { en piedras finas. }\end{array}$ \\
\hline $\begin{array}{l}\text { MOLETA. S. f. d. de MUELA. Dícese regularmente } \\
\text { de la que usan los pintores para moler los } \\
\text { colores. }\end{array}$ & $\begin{array}{l}\text { MOLETA. S. f. d. de MUELA. Piedra ó guijarro } \\
\text { comunmente de mármol, de figura cónica, } \\
\text { con que los pintores muelen los colores sobre } \\
\text { la losa, los boticarios algunas drogas en la } \\
\text { botica \&c. }\end{array}$ \\
\hline $\begin{array}{l}\text { RUEDA [2]. S. f. Circulo o corro formado de } \\
\text { algunas cosas. }\end{array}$ & $\begin{array}{l}\text { RuEDA [2]. S. f. Circulo o corro formado de } \\
\text { algunas cosas ó personas. }\end{array}$ \\
\hline $\begin{array}{l}\text { ZARANDAR. v. a. Limpiar el grano pasándolo } \\
\text { por la zaranda. }\end{array}$ & $\begin{array}{l}\text { ZARANDAR. v. a. Limpiar el grano ó la uva } \\
\text { pasándolo por la zaranda. }\end{array}$ \\
\hline
\end{tabular}

Tabla 7.

En alguna ocasión, puede introducirse toda una cadena de componentes donde no existía ninguno de ellos, como en la definición de la voz zapato.

\begin{tabular}{|c|c|}
\hline$D R A E 1817$ & DRAE 1822 \\
\hline $\begin{array}{l}\text { ZAPATO. S. m. El calzado del pie, que } \\
\text { ordinariamente se hace de piel adobada por } \\
\text { encima y suela por debajo. }\end{array}$ & $\begin{array}{l}\text { ZAPATO. S. m. El calzado del pie, que } \\
\text { ordinariamente se hace de piel de ante, cabra, } \\
\text { gamuza y otros cuadrúperos menores } \\
\text { adobada por encima, y de cuero de buey ó } \\
\text { vaca llamado suela por debajo. }\end{array}$ \\
\hline
\end{tabular}

Tabla 8 .

A diferencia de los casos anteriores en los que se incorporaba la información dentro de una misma oración (tabla 7 y 8), en las definiciones de las voces abrillantar y herméticamente se aumenta la descripción de las aplicaciones en una nueva oración introducida por algunas fórmulas estereotipadas como se dice también o se dice por extensión. 


\begin{tabular}{|c|c|}
\hline \multicolumn{1}{|c|}{$\boldsymbol{D R A E} \mathbf{1 8 1 7}$} & \multicolumn{1}{c|}{$\boldsymbol{D R A E} \mathbf{1 8 2 2}$} \\
\hline $\begin{array}{l}\text { ABRILLANTAR. v. a. Aumentar el brillo de } \\
\text { las piedras preciosas, especialmente de los } \\
\text { diamantes, labrándolas y puliéndolas. }\end{array}$ & $\begin{array}{c}\text { ABRILLANTAR. v. a. Aumentar el brillo de } \\
\text { las piedras preciosas, especialmente de los } \\
\text { diamantes, labrándolas y puliéndolas. Se dice } \\
\text { también de los metales y otras materias } \\
\text { duras. }\end{array}$ \\
\hline $\begin{array}{l}\text { HERMÉTICAMENTE. adv. m. Junto con el } \\
\text { verbo cerrar significa tapar una vasija por su } \\
\text { extremidad con la misma materia de que ella } \\
\text { es, ablandándola al fuego. }\end{array}$ & $\begin{array}{l}\text { HERMÉTICAMENTE. adv. m. Junto con el } \\
\text { verbo cerrar significa tapar una vasija por } \\
\text { su extremidad con la misma materia de que } \\
\text { ella es, ablandándola al fuego. Se dice por } \\
\text { extensión de todo lo que está bien tapado. }\end{array}$ \\
\hline
\end{tabular}

Tabla 9.

(b) Adición de información pertinente

Asimismo, también se puede añadir a la definición una nueva explicación o información que se considera relevante con el objetivo de hacerla más exacta. Algunos ejemplos son las voces fumoso, estar de media anqueta, cefálica, botella y romería.

\begin{tabular}{|c|c|}
\hline \multicolumn{1}{|c|}{ DRAE $\mathbf{1 8 1 7}$} & \multicolumn{1}{c|}{$\boldsymbol{D R \boldsymbol { R } \boldsymbol { E } \mathbf { 1 8 2 2 }}$} \\
\hline FUMOSO, SA. adj. Lo que despide humo. & $\begin{array}{c}\text { FUMOSO, SA. adj. Lo que abunda en humo, ó } \\
\text { lo despide en grande cantidad. }\end{array}$ \\
\hline $\begin{array}{c}\text { ESTAR DE MEDIA ANQUETA. Estar mal } \\
\text { sentado y con incomodidad }{ }^{21} \text {. }\end{array}$ & $\begin{array}{c}\text { ESTAR DE MEDIA ANQUETA Estar mal } \\
\text { sentado y con incomodidad ocupando solo } \\
\text { una cuarta parte del asiento. }\end{array}$ \\
\hline $\begin{array}{c}\text { CEFÁLICA. adj. Anat. que se aplica á la vena } \\
\text { superior del brazo llamada por eso de la } \\
\text { cabeza. }\end{array}$ & $\begin{array}{c}\text { CEFÁLICA. adj. Anat. que se aplica á la vena } \\
\text { superior del brazo llamada así por creerse } \\
\text { que sacaba la sangre de la cabeza. }\end{array}$ \\
\hline $\begin{array}{c}\text { BOTELLA. s. f. Redoma de vidrio muy doble, } \\
\text { con el cuello muy angosto, que comunmente } \\
\text { cabe media azumbre, y sirve para conservar } \\
\text { los líquidos. }\end{array}$ & $\begin{array}{c}\text { BOTELLA. s. f. Redoma de vidrio muy doble, } \\
\text { con el cuello muy angosto, que comunmente } \\
\text { cabe menos de media azumbre, y sirve para } \\
\text { conservar los líquidos. }\end{array}$ \\
\hline
\end{tabular}

Tabla 10.

Las modificaciones realizadas en los ejemplos anteriores comportan un aumento del enunciado definicional.

(c) Cambio de una palabra por otra o por su explicación

Por último, se ha observado que para precisar la definición se suele cambiar una palabra por otra más pertinente o por una explicación de su significado.

21 Esta voz se debe buscar en el diccionario después de anque para la edición de 1817 y de anotar para la de 1822. En 1832 ya aparece bajo el lema anqueta (estar de media). 
En algunas ocasiones el vocablo se reemplaza por otro de uso más frecuente en la época. Como se ha indicado anteriormente, en el prólogo de esta edición se muestra la preocupación que existía por "dar mayor claridad usando de términos comunes á las definiciones", algo que sucede, por ejemplo, en las voces naturaleza [2], rueda, abrojo [4], borren y dificultar.

\begin{tabular}{|c|c|}
\hline \multicolumn{1}{|c|}{$\boldsymbol{D R} \boldsymbol{A E} \mathbf{1 8 1 7}$} & $\boldsymbol{D R A E} \mathbf{1 8 2 2}$ \\
\hline $\begin{array}{c}\text { NatuRALEZA [2]. s. f. El agregado, orden y } \\
\text { disposición de todas las unidades que } \\
\text { componen el universo. }\end{array}$ & $\begin{array}{c}\text { NATURALEZA [2]. s. f. El conjunto, orden } \\
\text { y disposición de todas las unidades que } \\
\text { componen el universo. }\end{array}$ \\
\hline $\begin{array}{l}\text { RUEDA. s. f. Máquina orbicular y rotunda que } \\
\text { facilmente gira y da vueltas al rededor. }\end{array}$ & $\begin{array}{l}\text { RUEDA. s. f. Máquina orbicular y redonda que } \\
\text { gira sobre un eje y da vueltas al rededor }\end{array}$ \\
\hline
\end{tabular}

Tabla 11.

Como se observa en la tabla 11, en la voz naturaleza, los términos agregado y conjunto que se alternan en la edición de 1817 y la de 1822 son sinónimos, ya que en 1822 la definición de agregado [2] es "el conjunto de muchas ó varias cosas" y la de conjunto [4] es "el agregado de muchas cosas" 22 . No obstante, en 1822 se reemplaza agregado por conjunto, posiblemente por considerar que esta segunda palabra era más usual ${ }^{23}$. En cambio, en el enunciado definicional de rueda, la modificación está motivada por el tratamiento que reciben las variantes rotunda y redonda en el propio diccionario, puesto que esta última es la forma preferida por la Academia y, por lo tanto, la primera remite a la segunda: ROTUNDO, DA. adj. REDONDO (DRAE 1822). En estos casos, tal y como se señala en el prólogo, la voz que aparece definida "basta para indicar que esta es la mas propia y de un uso mas comun y constante" (DRAE 1822: prólogo).

Pero no siempre el diccionario es consecuente con la regla de utilizar un término más usual, una excepción es fundición [3] en cuya definición la palabra desplazada es conjunto $^{24}$.

\begin{tabular}{|c|c|}
\hline \multicolumn{1}{|c|}{$\boldsymbol{D R A E} \mathbf{1 8 1 7}$} & $\boldsymbol{D R A E} \mathbf{1 8 2 2}$ \\
\hline $\begin{array}{c}\text { FunDICIÓN [3]. s. f. Conjunto ó agregado de todos } \\
\text { los moldes ó letras que son necesarias para } \\
\text { una impresión. }\end{array}$ & $\begin{array}{r}\text { FunDICIÓN [3]. s. f. El surtido ó agregado de todos } \\
\text { los moldes ó letras de una clase para imprimir. }\end{array}$ \\
\hline
\end{tabular}

Tabla 12.

22 La voz conjunto se incluyó por primera vez en el diccionario académico en la edición de 1817.

23 Así lo determinan los datos que se han obtenido en $C O R D E$, puesto que los resultados indican que, para esta acepción, el sustantivo conjunto es mucho más usado que el sustantivo agregado, por lo que se puede deducir que era la más común. La primera palabra se encuentra en 46 casos repartidos en 28 obras distintas y la segunda en 4 casos repartidos en 3 obras distintas.

24 Según los datos del CORDE, en la época en que se redactó la edición de 1822 (para establecer la época se han seleccionado los textos de entre 1800 y 1822), la palabra conjunto se encuentra en 46 casos repartidos en 28 obras distintas y la palabra surtido se encuentra en 9 casos repartidos en 6 obras distintas. 
En otras ocasiones, el motivo de reemplazar una voz por otra es, probablemente, porque la palabra desplazada no aparece definida en el propio diccionario; tal es el caso de pedicox en cuya definición se halla el vocablo cojuela, el cual no aparece registrado en la propia obra (y tampoco se registrará en ninguna de las ediciones siguientes). Un caso parecido es el de abridero [2], que cambia el término melocotonero por melocotón, posiblemente porque la voz melocotonero no estaba registrada en la nomenclatura de la edición de 1822. En este caso, el término sí que entrará posteriormente en el lemario del diccionario (en la edición de 1884), quizás, justamente, porque el vocablo aparece en la definición de abridero.

\begin{tabular}{|c|c|}
\hline \multicolumn{1}{|c|}{ DRAE $\mathbf{1 8 1 7}$} & $\boldsymbol{D R A E} \mathbf{1 8 2 2}$ \\
\hline $\begin{array}{c}\text { PEDICOX. s. m. El salto que se da con un pie } \\
\text { solo, que vulgarmente se dice coJuELA ó á pie } \\
\text { COJUELA. }\end{array}$ & $\begin{array}{c}\text { PEDICOX. s. m. El salto que se da con un pie } \\
\text { solo, que vulgarmente se dice Á LA PATA COJA. }\end{array}$ \\
\hline $\begin{array}{c}\text { ABRIDERO [2]. s. m. Árbol, variedad del } \\
\text { melocotonero comun, del que se diferencia } \\
\text { en que su fruta tiene el hueso desasiado de la } \\
\text { carne ó pulpa. }\end{array}$ & $\begin{array}{c}\text { ABRIDERO [2]. s. m. Árbol, variedad del } \\
\text { melocoton comun, que produce una fruta } \\
\text { del mismo nombre, que se abre por medio, } \\
\text { y suelta el hueso con mucha facilidad y sin } \\
\text { carne ninguna. }\end{array}$ \\
\hline
\end{tabular}

\section{Tabla 13.}

A diferencia de los ejemplos anteriores (tabla 13) en los que no aparecía la voz desplazada en la nomenclatura del diccionario, en sarmentador, ejemplificado en la tabla 14, se sustituye el verbo coger por recoger, ya que en esta misma edición al verbo recoger se le añade una nueva acepción con el significado de "Hacer la recolección de los frutos, coger la cosecha" (DRAE 1822: s. v. recoger [4]).

\begin{tabular}{|c|c|}
\hline \multicolumn{1}{|c|}{$\boldsymbol{D R A E} \mathbf{1 8 1 7}$} & $\boldsymbol{D R A E} \mathbf{1 8 2 2}$ \\
\hline $\begin{array}{c}\text { SARMENTADOR, RA. s. m. y f. El que coge los } \\
\text { sarmientos podados. }\end{array}$ & $\begin{array}{l}\text { SARMENTADOR, RA. s. m. y f. El que recoge } \\
\text { los sarmientos podados para formar con ellos } \\
\text { hacecillos. }\end{array}$ \\
\hline
\end{tabular}

Tabla 14.

Finalmente, en algunas definiciones la palabra no se reemplaza por otra sino por una explicación de su significado, ampliando así el enunciado definicional. Son algunos ejemplos de ello las voces comporta, pediluvios, casar la pensión (s. v. pensión).

\begin{tabular}{|c|c|}
\hline DRAE $\mathbf{1 8 1 7}$ & \multicolumn{1}{c|}{$\boldsymbol{D R A E} \mathbf{1 8 2 2}$} \\
\hline $\begin{array}{c}\text { COMPORTA. s. f. En algunas partes el cuévano } \\
\text { para trasportar las uvas en la vendimia. }\end{array}$ & $\begin{array}{l}\text { COMPORTA. s. f. Cubeta abierta mas ancha } \\
\text { por arriba que por abajo, de que en algunas } \\
\text { partes usan para trasportar las uvas en la } \\
\text { vendimia. }\end{array}$ \\
\hline
\end{tabular}




\begin{tabular}{|c|c|}
\hline \multicolumn{1}{|c|}{$\boldsymbol{D R} \boldsymbol{A E} \mathbf{E} \mathbf{1 8 1 7}$} & \multicolumn{1}{c|}{ DRAE $\mathbf{1 8 2 2}$} \\
\hline $\begin{array}{c}\text { PEDILUVIOS. s. m. p. Baños en los pies para } \\
\text { atraer á ellos los humores }\end{array}$ & $\begin{array}{l}\text { PEDILUVIOS. s. m. p. Baños en los pies } \\
\text { para atraer á ellos el calor que se haya } \\
\text { concentrado en la cabeza ú otra parte del } \\
\text { cuerpo. }\end{array}$ \\
\hline
\end{tabular}

Tabla 15.

\subsubsection{Reescritura de las definiciones}

El segundo procedimiento para clarificar la redacción de las definiciones consiste en reescribirlas enteramente, por lo que estas voces experimentan cambios de mayor calado que los expuestos en $\S$ 4.1.1. Algunos ejemplos de ello son equilibrio, penetrador, equivalencia y anónimo.

\begin{tabular}{|c|c|}
\hline$D R A E 1817$ & $D R A E 1822$ \\
\hline $\begin{array}{l}\text { EQUILIBRIO. s. m. Peso que iguala á otro peso, } \\
\text { ó la acción de equilibrar dos pesos. }\end{array}$ & $\begin{array}{l}\text { EQUILIBRIO. s. m. Igualdad de dos ó mas pesos } \\
\text { ó fuerzas que se contrarestan, u destruyendo } \\
\text { recíprocamente sus efectos, quedan sin } \\
\text { movimiento. }\end{array}$ \\
\hline PENETRADOR, RA s. m. y f. El que penetra & $\begin{array}{l}\text { PENETRADOR, RA s. m. y f. Agudo, perspicaz, } \\
\text { sutil, el que es de vivo ingenio. }\end{array}$ \\
\hline $\begin{array}{l}\text { EQUIVALENCIA. s. f. Compensación ó } \\
\text { precio que se da por alguna cosa igualando } \\
\text { la estimación de lo que se da y de lo que se } \\
\text { recibe. }\end{array}$ & $\begin{array}{l}\text { EQUIVALENCIA. s. f. Igualdad en el valor, } \\
\text { estimación y aprecio de dos ó mas cosas. }\end{array}$ \\
\hline
\end{tabular}

Tabla 16.

Como se puede observar en la tabla 16, en la definición de la voz penetrador, el cambio parece estar motivado por salir de la circularidad entre el lema y la definición más que por ofrecer una explicación más entendedora.

En algunas ocasiones, la reescritura comporta una reducción de la extensión del enunciado definicional mediante la supresión de acepciones secundarias introducidas por fórmulas metalingüísticas como se usa también o llámese así también. Son ejemplos de ello las palabras gozo [3], gota o rufián. En el estudio de Freixas (2018: 155) se ha comprobado que el uso de estas fórmulas perdura en el diccionario académico durante todo el siglo XIX, incluso algunas no se eliminarán hasta finales del XX.

25 Los datos analizados parecen indicar que hay una determinación de sustituir o eliminar la palabra humores de las definiciones, que según el diccionario académico es la "sustancia tenue y fluida del cuerpo del animal" (DRAE 1822: s. v. humor), pero, a pesar de ello, esta palabra subsistirá aun en el diccionario durante todo el siglo XIX. La sustitución o supresión de la voz humores en el diccionario académico se llevará a cabo durante todo el siglo XIX. Son ejemplo de ello las voces complexión, resudación, resudar, en las que se elimina este término en 1822, temperamento [3], en la que se sustituye en 1852, mordicación, purgar [6], en 1869, y retroceso [2], pletórico y purga en 1884 


\begin{tabular}{|c|c|}
\hline$D R A E 1817$ & $D R A E 1822$ \\
\hline $\begin{array}{l}\text { GOTA. s. f. partecilla de agua ú otro licor. Se usa } \\
\text { tambien para expresar la grande escasez de } \\
\text { alguna cosa; y asi se dice: no ha llovido GOTA. }\end{array}$ & GOTA. S. f. partecilla de agua ú otro licor. \\
\hline $\begin{array}{l}\text { RUFIAN. s. m. El que trata y vive } \\
\text { deshonestamente con mugeres, solicitándolas } \\
\text { ó consintiéndoles el trato con otros hombres. } \\
\text { Llámase asi tambien el que por causas } \\
\text { torpes tiene pendencia. }\end{array}$ & $\begin{array}{l}\text { RUFIAN. S. m. El que hace el infame tráfico de } \\
\text { mugeres públicas. }\end{array}$ \\
\hline
\end{tabular}

Tabla 17.

En otras ocasiones, el replanteamiento del enunciado definicional implica un cambio en la manera de definir, hecho que tiene consecuencias importantes en el tipo de definición. Este es el caso de anisado o erispela. En la primera voz se pasa de una definición impropia a una propia, utilizando la terminología de Seco (1987: 22). Así, en la edición de 1822 se elimina la fórmula metalingüística aplíquese a y se puede poner en práctica el principio de sustituibilidad otorgado a las definiciones propias. En cambio, la voz erisipela se define en 1822 mediante una relación de hiperonimia inexistente en la edición de 1817.

\begin{tabular}{|l|l|}
\hline \multicolumn{1}{|c|}{$\boldsymbol{D R} \boldsymbol{A E} \mathbf{E} \mathbf{1 8 1 7}$} & \multicolumn{1}{c|}{$\boldsymbol{D R A E} \mathbf{1 8 2 2}$} \\
\hline $\begin{array}{l}\text { ANISADO, DA. adj. Aplíquese al aguardiente y } \\
\text { otros licores que se componen de anís. }\end{array}$ & $\begin{array}{l}\text { ANISADO, DA. adj. Compuesto ó aderezado } \\
\text { con anís, ó lo que sabe á él. }\end{array}$ \\
\hline $\begin{array}{l}\text { ERISIPELA. s. f. Inflamacion y encendimiento } \\
\text { de la sangre detenida en los vasos del cutis. }\end{array}$ & $\begin{array}{l}\text { ERISIPELA. s. f. Enfermedad que consiste en } \\
\text { la inflamacion de la sangre, y se descubre por } \\
\text { el color encendido y por algunos granos en } \\
\text { el cutis. }\end{array}$ \\
\hline
\end{tabular}

Tabla 18.

Finalmente, cabe destacar que los refranes han sido motivo de especial atención a la hora de revisar las definiciones, experimentando, algunas de ellas, modificaciones sustanciales. Son ejemplos de ello quien no adoba ó quita gotera hace casa entera (s. v. gotera), molinillo casado te veas, que asi rabeas (s. v. molinillo) y ruin sea quien por ruin se tiene (s. v. ruin), abril, aguas mil.

\begin{tabular}{|c|c|}
\hline DRAE 1817 & DRAE $\mathbf{1 8 2 2}$ \\
\hline $\begin{array}{c}\text { QUIEN NO ADOBA Ó QUITA GOTERA HACE CASA ENTERA. } \\
\text { ref. Que enseña el cuidado que se debe tener } \\
\text { en quitar los inconvenientes aunque pequeños, } \\
\text { porque de ellos suelen resultar graves daños. }\end{array}$ & $\begin{array}{c}\text { QUIEN NO ADOBA Ó QUITA GOTERA HACE CASA ENTERA. } \\
\text { ref. Que enseña el cuidado con que se debe } \\
\text { acudir al remedio de los males en sus } \\
\text { principios antes de que sean grandes. }\end{array}$ \\
\hline
\end{tabular}




\begin{tabular}{|c|c|}
\hline \multicolumn{1}{|c|}{$\boldsymbol{D R A E} \mathbf{1 8 1 7}$} & DRAE 1822 \\
\hline $\begin{array}{c}\text { MOLINILLO CASADO TE VEAS, QUE ASI RABEAS.ref. que } \\
\text { enseña cuanto amoldan los trabajos aun al } \\
\text { mas fuerte y robusto. }\end{array}$ & $\begin{array}{c}\text { MOLINILLO CASADO TE VEAS, QUE ASI RABEAS. ref. } \\
\text { que enseña cuanto amoldan los cuidados } \\
\text { y penalidades del matrimonio aun al mas } \\
\text { fuerte y robusto. }\end{array}$ \\
\hline $\begin{array}{c}\text { RUIN SEA QUIEN POR RUIN SE TIENE. ref. que amonesta } \\
\text { a no sentir tan bajamente de sí que no nos } \\
\text { alabemos con modestia alguna vez. }\end{array}$ & $\begin{array}{c}\text { RUIN SEA QUIEN POR RUIN SE TIENE. ref. que } \\
\text { amonesta a no sentir tan bajamente de sí que } \\
\text { se de ocasion á ser mirado con desprecio. }\end{array}$ \\
\hline $\begin{array}{c}\text { ABRIL AGUAS MIL. ref. Que manifiesta lo útiles que } \\
\text { en este mes suelen ser las aguas. }\end{array}$ & $\begin{array}{c}\text { ABRIL AGUAS MIL. ref. Que manifiesta lo } \\
\text { abundantes que en este mes suelen ser las } \\
\text { aguas. }\end{array}$ \\
\hline
\end{tabular}

Tabla 19.

Un caso especial es el del refrán abril, aguas mil que, a pesar de no reescribirse enteramente su definición, el cambio del término útil por el de abundante provoca una modificación del significado. A lo largo de la tradición lexicográfica, este refrán ha ido intercambiando en su definición ambas voces. En el diccionario de Covarrubias (1611) aparece el significado que se refiere a la utilidad que tienen las aguas en este mes: "Por que en ese tiempo tienen necessidad del agua los panes, y las plantas". En la primera edición del Diccionario de autoridades (1726) se añade también el significado de la abundancia: "que se dice, porque en este mes tiene necesidad del agua los panes y las plantas, ó porque en él suele llover muchas veces". A partir de la segunda edición del Diccionario de autoridades (1770) y hasta la quinta edición del Diccionario usual (1817) solamente se mantiene el significado de útil (sentido figurado). Finalmente, a partir de la sexta edición el único significado que aparece es el de abundante (sentido literal).

\subsection{Reducción de las definiciones}

Uno de los objetivos que se planteó la Academia en la redacción de la sexta edición del diccionario fue la reducción de la obra lexicográfica, además de a nivel macroestructural, reflejado en la notable supresión de lemas, también microestructural, puesta en práctica con la disminución de las definiciones de las voces. En este sentido, la revisión de la obra está marcada por un afán economizador que culminará en la edición siguiente de 1832, formando ambas parte de un mismo proceso evolutivo en el diccionario usual.

Se han detectado varios tipos de intervenciones para reducir las definiciones en la sexta edición: (§ 4.2.1.) eliminación de voces y expresiones redundantes, (§ 4.2.2.) supresión de algunas fórmulas definitorias y (§ 4.2.3.) disminución de la información enciclopédica que contenían algunas de las voces que componen el lemario. En los procedimientos $\S$ 4.2.1. y $\S$ 4.2.2. se suprimen partes irrelevantes de la definición que no afectan al contenido de la misma. En cambio, en $\S$ 4.2.3. se suprime una parte del contenido, aunque esta información aporte datos adicionales y de menor relevancia para comprender la voz que se está definiendo. 


\subsubsection{Supresión de voces y expresiones redundantes}

El primero de los tres procedimientos indicados anteriormente, supresión de voces y expresiones redundantes, es uno de los más usuales en la sexta edición para la reducción de las definiciones. En algunos casos, la información omitida se considera redundante porque una de las voces que se encuentra en la definición significa lo mismo que la parte eliminada. Son ejemplos de ello los términos fulgurar, orladura [2], rueda de santa Catalina [2] (s. v. rueda), destapiar, erar, por fuerza (s. v. fuerza), pentagrama y roncón:

\begin{tabular}{|c|c|}
\hline \multicolumn{1}{|c|}{ DRAE 1817} & DRAE 1822 \\
\hline $\begin{array}{c}\text { FULGURAR. v. n. Poét. Despedir resplandores, } \\
\text { echar rayos de luz. }\end{array}$ & FULGURAR. v. n. Poét. Despedir rayos de luz. \\
\hline $\begin{array}{c}\text { ORLADURA. Lo mismo que oRLA por la orilla ó } \\
\text { borde de alguna cosa. }\end{array}$ & ORLADURA. ORLA por la orilla. \\
\hline $\begin{array}{c}\text { RUEDA DE SANTA CATALINA. La que los saludadores } \\
\text { fingidos se hacen estampar en alguna parte } \\
\text { del cuerpo, y blasonan muchas veces tener } \\
\text { impresa en su paladar. }\end{array}$ & $\begin{array}{l}\text { RUEDA DE SANTA CATALINA. La que los saludadores } \\
\text { se hacen estampar en alguna parte del cuerpo, } \\
\text { paladar. }\end{array}$ \\
\hline
\end{tabular}

Tabla 20 .

Como se observa en la tabla 20, en la definición de fulgurar se ha omitido la voz resplandores, que aparece definida en el diccionario como "la luz muy clara que arroja o despide el sol u otro cualquier cuerpo luminoso". Por lo tanto, la información que se mantiene en 1822 es exactamente la misma que en la edición anterior. Lo mismo ocurre en orladura y en rueda de santa Catalina. En la primera, la expresión suprimida es equivalente a la voz que se mantiene, puesto que borde se define como el "extremo ú orilla de alguna cosa" (DRAE 1822: s. v. borde). En la segunda, el adjetivo omitido es redundante, ya que, teniendo en cuenta la definición que aparece en el diccionario, todos los saludadores son fingidos: "El impostor que aparenta curar ó precaver la rabia ú otros males con el aliento, la saliva y con ciertas deprecaciones y fórmulas" (DRAE 1822: s. v. saludador).

También se considera innecesaria la información que se elimina en los términos ceceo y equiponderante, en esta ocasión, porque dicha información ya se encuentra en el infinitivo. Mediante esta intervención se evitan las repeticiones de contenido en los artículos.

\begin{tabular}{|c|c|}
\hline$D R A E 1817$ & $D R A E 1822$ \\
\hline CECEAR. v. a. Pronunciar la $s$ como $c$. & CECEAR. v. a. Pronunciar la $s$ como $c$. \\
\hline $\begin{array}{l}\text { CECEO. s. m. La accion y efecto de cecear ó de } \\
\text { pronunciar la } s \text { como } c \text {. }\end{array}$ & CECEO. s. m. La accion y efecto de cecear. \\
\hline
\end{tabular}

Tabla 21. 
Asimismo, otro de los recursos utilizados para eliminar información redundante es la supresión de sinónimos en una definición en la que se enumeran varios de ellos. Algunos ejemplos son destajador, ruin [4], rufo [2], erección, funeral [2], hacer ruido (s. v. ruido), ruego o zar:

\begin{tabular}{|c|c|}
\hline \multicolumn{1}{|c|}{$\boldsymbol{D R A E} \mathbf{1 8 1 7}$} & $\boldsymbol{D R A E} \mathbf{1 8 2 2}$ \\
\hline $\begin{array}{c}\text { DESTAJADOR. s. m. Especie de martillo de } \\
\text { que se sirven los herreros para poner ya en } \\
\text { redondo, ya en cuadrado el hierro encendido } \\
\text { ó caldeado, según lo necesitan. }\end{array}$ & $\begin{array}{c}\text { DESTAJADOR. s. m. Especie de martillo de } \\
\text { que se sirven los herreros para poner ya en } \\
\text { redondo, ya en cuadrado el hierro caldeado. }\end{array}$ \\
\hline $\begin{array}{c}\text { RUIN [4]. El mezquino, miserable, escaso y } \\
\text { avariento. }\end{array}$ & RUIN [4]. El mezquino, y avariento. \\
\hline $\begin{array}{c}\text { RUFo [2]. Se dice también el que tiene el pelo } \\
\text { ensortijado, duro y áspero ó encrespado. }\end{array}$ & $\begin{array}{c}\text { RUFo [2]. Se dice también el que tiene el pelo } \\
\text { ensortijado. }\end{array}$ \\
\hline
\end{tabular}

Tabla 22.

En algunos casos resulta difícil comprobar si el objetivo de las enmiendas era reducir sinónimos o subsanar errores, como en gracia de dios (s. v. gracia) "Entre gente rústica y traginadora ${ }^{26}$ el pan [...]" (DRAE 1817) o en equidad "Igualdad, rectitud" (DRAE 1817), puesto que la palabra omitida en la edición de 1822 no se define como sinónima de la que se mantiene. A diferencia de lo que ocurre, por ejemplo, en las voces suprimidas en la definición de ruin [4]: escaso se define como "mezquino, nada liberal ni dadivoso" y miserable como "avariento, escaso y apocado" (DRAE 1822).

Finalmente, en algunas definiciones se opta por usar una voz más genérica que incluya las palabras suprimidas en la edición de 1822. Este término menos determinado puede tratarse de una voz más general, como en era o abrutado, o de una palabra comodín, como en la definición de erección [2] o erector, en las que se ha optado por conservar el término cosa y suprimir el de carácter más específico:

\begin{tabular}{|c|c|}
\hline \multicolumn{1}{|c|}{ DRAE 1817 } & DRAE 1822 \\
\hline $\begin{array}{c}\text { ERA [5]. El cuadro ó plantel de tierra en que el } \\
\text { hortelano siembra lechugas, berzas y otras } \\
\text { legumbres. }\end{array}$ & $\begin{array}{c}\text { ERA [5]. El cuadro ó plantel de tierra en que el } \\
\text { hortelano siembra y cultiva verduras. }\end{array}$ \\
\hline $\begin{array}{l}\text { ERECCION [2]. Fundacion, institución ó colocacion } \\
\text { de alguna memoria ó cosa. }\end{array}$ & $\begin{array}{l}\text { ERECCION [2]. Fundacion ó institucion de alguna } \\
\text { cosa. }\end{array}$ \\
\hline
\end{tabular}

Tabla 23 .

\subsubsection{Supresión de fórmulas definitorias}

En segundo lugar, tal y como se señala en el prólogo, otro de los procedimientos que se plantean para abreviar las definiciones es la supresión de algunas fórmulas y artículos que

26 El término traginador, ra no aparece recogido en ninguna edición del diccionario. Sí se hallan, en cambio, las voces traginante y traginero, ambas con $g$ hasta la edición de 1822. A partir de 1832 se escriben con $j$. 
no influyen en el significado de la unidad léxica que se está definiendo pero que modifican la sintaxis del enunciado definicional y, por lo tanto, tienen implicaciones importantes en el tipo de definición.

Teniendo en cuenta esta directriz, se elimina del principio de las definiciones el artículo determinado lo/la y los pronombres indefinidos cierto y cualquiera. Algunos ejemplos de ello son las definiciones de las voces freza [1], [2], [3], hucha [1], [2], [3], hormigón, función [1], [2], [3], [5], fresneda, fritada, fumorola, hila real de agua (s. v. hila), hilo de perlas, holandillao hule [1], [2]:

\begin{tabular}{|c|c|}
\hline \multicolumn{1}{|c|}{ DRAE 1817 } & DRAE 1822 \\
\hline $\begin{array}{c}\text { FreZa [2]. Mont. La señal ú hoyo que hace algun } \\
\text { animal escarbando ó hozando. }\end{array}$ & $\begin{array}{c}\text { FrEZA [2]. Mont. Señal ú hoyo que hace algun } \\
\text { animal escarbando ó hozando. }\end{array}$ \\
\hline $\begin{array}{c}\text { Hucha [2]. Cierta vasija de barro para guardar el } \\
\text { dinero, que por otro nombre se llama alcancía. }\end{array}$ & $\begin{array}{c}\text { HuCHA [2]. Vasija de barro para guardar el dinero, } \\
\text { que por otro nombre se llama alcancía. }\end{array}$ \\
\hline $\begin{array}{c}\text { HORMIGON. s. m. Cierta mezcla compuesta de } \\
\text { piedras menudas, cal y betun, la cual es tan } \\
\text { fuerte y sólida que dura siglos, y tan firme } \\
\text { como la piedra. }\end{array}$ & $\begin{array}{c}\text { HORMIGON. s. m. Mezcla compuesta de piedras } \\
\text { menudas, cal y betun, la cual es tan fuerte y } \\
\text { sólida que dura siglos, y tan firme como la } \\
\text { piedra. }\end{array}$ \\
\hline $\begin{array}{c}\text { Funcion [2]. Cualquiera de las acciones y } \\
\text { ejercicios propios de algun empleo, facultad } \\
\text { ú oficio. }\end{array}$ & $\begin{array}{c}\text { Funcion [2]. Accion y ejercicio de algun empleo, } \\
\text { facultad ú oficio. }\end{array}$ \\
\hline
\end{tabular}

\section{Tabla 24.}

Sin embargo, esta supresión no se lleva a cabo de manera sistemática, puesto que el adjetivo indeterminado cierto se mantiene en algunas voces como denario, dentellon, derecho de espada (s. v. derecho) o espinape, en las que se eliminará en las ediciones de final de siglo (DRAE 1884 y 1899).

También es destacable la eliminación de la fórmula definitoria especie de. Esta expresión se utiliza para señalar dos tipos diferentes de vínculo entre la definición y el lema: por un lado, establece una relación de hiperonimia y, por el otro, una relación de semejanza. En el primer tipo, el empleo de dicha fórmula es inclusivo, es decir, indica la pertenencia a una clase o conjunto. Detrás aparece el hiperónimo y las características individuales que diferencian al lema del resto de co-hipónimos. En este caso, se puede prescindir de su empleo sin alterar el significado de la unidad léxica. En el segundo tipo, dicha fórmula se utiliza para comparar el lema con otro ser u objeto que aparece en la propia definición. En este caso, la eliminación de la expresión especie de influye en el significado de la voz que se está definiendo. Habitualmente esta fórmula se suprime en las definiciones hiperonímicas, como en frisado [2], hilo de monjas, rompecoches, hilo de cartas e hilo primo.

\begin{tabular}{|c|c|}
\hline \multicolumn{1}{|c|}{$\boldsymbol{D R} \boldsymbol{A E} \mathbf{E} \mathbf{1 8 1 7}$} & $\boldsymbol{D R A E} \mathbf{1 8 2 2}$ \\
\hline $\begin{array}{c}\text { FRISADO [2]. s. m. Especie de tejido de seda, } \\
\text { llamado así porque se frisaba y levantaba el } \\
\text { pelo formando unas bolillas. }\end{array}$ & $\begin{array}{c}\text { FRISADO [2]. s. m. Tejido de seda, llamado así } \\
\text { porque se frisaba y levantaba el pelo formando } \\
\text { unas bolillas. }\end{array}$ \\
\hline
\end{tabular}




\begin{tabular}{|c|c|}
\hline$D R A E 1817$ & $D R A E 1822$ \\
\hline $\begin{array}{l}\text { HILO DE MONJAS. Especie de hilo fino llamado } \\
\text { así porque le labran en varios conventos de } \\
\text { monjas. }\end{array}$ & 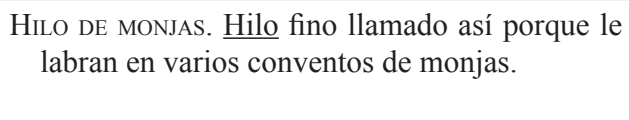 \\
\hline $\begin{array}{l}\text { ROMPECOCHES. s. m. Especie de tejido fuerte } \\
\text { que mas comunmente se llama PERDURABLE. }\end{array}$ & $\begin{array}{l}\text { ROMPECOCHES. s. m. Tejido fuerte que mas } \\
\text { comunmente se llama PERDURABLE. }\end{array}$ \\
\hline
\end{tabular}

Tabla 25.

No obstante, especie de se elimina también en la definición de la voz hernia, en la que la relación que establece es comparativa: "HERNIA. s. f. Una especie de saco, que por la prolongacion del peritóneo se forma en el ombligo ó las ingles [...]" (DRAE 1817). Como se puede observar, hernia no es una variedad de saco, a diferencia de, por ejemplo, frisado [2], que sí es una subclase de tejido. En este caso, especie de indica que hernia tiene características que lo asemejan con un saco pero no es un saco. El método comparativo es habitual, como ha observado Gómez de Enterría (2018: 293), en las voces de la historia natural, sobre todo, en las que denominan animales (véase la definición de anta en la tabla 30).

Un caso similar es la supresión de los verbos llamar y ser, los cuales expresan una equivalencia entre el lema y el enunciado definicional. Estos verbos suelen aparecer introduciendo toda la definición, como, por ejemplo, en pensionario [2], hilo de vela (s. v. hilo) o pechuga [2].

\begin{tabular}{|c|c|}
\hline \multicolumn{1}{|c|}{$\boldsymbol{D R} \boldsymbol{A E} \mathbf{1 8 1 7}$} & $\boldsymbol{D R A E} \mathbf{1 8 2 2}$ \\
\hline $\begin{array}{c}\text { PENSIONARIO [2]. Es el consejero, abogado ó } \\
\text { dignidad de letras en alguna república. }\end{array}$ & $\begin{array}{c}\text { PENSIONARIO [2]. El consejero, abogado ó dignidad } \\
\text { de letras en alguna república. }\end{array}$ \\
\hline $\begin{array}{c}\text { HILO DE VELA. En la marina se llama asi el hilo de } \\
\text { cáñamo mas grueso que el regular, con el cual } \\
\text { se cosen las velas de las embarcaciones. }\end{array}$ & $\begin{array}{c}\text { HILO DE VELA. En la marina el hilo de cáñamo mas } \\
\text { grueso que el regular, con el cual se cosen las } \\
\text { velas de las embarcaciones. }\end{array}$ \\
\hline $\begin{array}{l}\text { PECHUGA [2]. met. y fam. Llaman al pecho del } \\
\text { hombre ó muger. }\end{array}$ & $\begin{array}{l}\text { PECHUGA [2]. met. y fam. El pecho del hombre ó } \\
\text { muger. }\end{array}$ \\
\hline
\end{tabular}

Tabla 26.

El verbo copulativo ser, por su parte, también puede aparecer precedido de la fórmula metalingüística hablando de $e^{27}$. En la entrada herir [4], [5] y [6], esta eliminación se lleva a cabo en las acepciones 4, 5 y 6, pero se mantiene en la acepción 3, del mismo modo que se conserva en otras voces como en pasar [11], lento [3] o recibirse (s. v. recibir).

\begin{tabular}{|c|c|}
\hline \multicolumn{1}{|c|}{$\boldsymbol{D} \boldsymbol{A E} \mathbf{E} \mathbf{1 8 1 7}$} & $\boldsymbol{D R} \boldsymbol{A E} \mathbf{1 8 2 2}$ \\
\hline $\begin{array}{c}\text { HERIR [3]. Hablando del sol es bañar alguna cosa, } \\
\text { esparcir ó tender sobre ella sus rayos. }\end{array}$ & $\begin{array}{c}\text { HERIR [3]. Hablando del sol es bañar alguna cosa, } \\
\text { esparcir ó tender sobre ella sus rayos. }\end{array}$ \\
\hline $\begin{array}{c}\text { HERIR [4]. Hablando de instrumentos de cuerda es } \\
\text { pulsarlos, tocarlos. }\end{array}$ & $\begin{array}{c}\text { HERIR [4]. Hablando de instrumentos de cuerda } \\
\text { pulsarlos, tocarlos. }\end{array}$ \\
\hline
\end{tabular}

27 Solamente se ha encontrado que se elimina el verbo ser en algunas acepciones de la entrada herir. 


\begin{tabular}{|c|c|}
\hline DRAE 1817 & DRAE 1822 \\
\hline $\begin{array}{c}\text { HERIR [5]. Hablando del oido ó de la vista es } \\
\text { hacer los objetos en estos sentidos impresion, } \\
\text { causar en ellos alguna sensacion. }\end{array}$ & $\begin{array}{c}\text { HERIR [5]. Hablando del oido ó de la vista hacer } \\
\text { los objetos en estos sentidos impresion, } \\
\text { causar en ellos alguna sensacion. }\end{array}$ \\
\hline $\begin{array}{c}\text { HERIR [6]. met. Hablando del alma ó del corazón } \\
\text { es mover, excitar algun efecto. }\end{array}$ & $\begin{array}{c}\text { HERIR [6]. met. Hablando del alma ó del corazon } \\
\text { mover, excitar algun efecto. }\end{array}$ \\
\hline $\begin{array}{c}\text { PASAR [11]. Hablando de dinero ú otras especies } \\
\text { que se han contado es volverlas á contar. }\end{array}$ & $\begin{array}{c}\text { PASAR [11]. Hablando de dinero ú otras especies } \\
\text { que se han contado es volverlas á contar. }\end{array}$ \\
\hline
\end{tabular}

Tabla 27.

Cuando la fórmula hablando de aparece con otros verbos similares que también expresan la equivalencia entre el lema y la definición (significar y decir) estos suelen mantenerse, como, por ejemplo, en pasar [7]: "Hablando de géneros prohibidos ó que adeudan derechos significa introducirlos ó extraerlos sin registro" (DRAE 1817-1822), o en alto [7]: "Hablando de la situacion de las calles, provincias ó paises se dice de los que estan mas altos" (DRAE 1817-1822).

Finalmente, existe cierta tendencia a eliminar las fórmulas estereotipadas "bien conocido/da" o "muy conocido/da", que, tal y como se señala en las investigaciones de Freixas (2012: 309; 2018: 145-146), se habían utilizado en ediciones anteriores a la estudiada para definir "cosas universalmente conocidas" y así evitar una explicación demasiado abundante de la voz. Sin embargo, el empleo de dicha fórmula no impedía una descripción detallada de la palabra, por lo que ambos recursos convivieron en una misma definición en las ediciones de 1770 a 1817. A partir de la sexta edición del diccionario se prescinde de esta fórmula tanto en las definiciones que designan objetos como en las que denominan plantas y animales. Algunos ejemplos son las definiciones de las voces peso [9], pólvora, sarampión, crea, romero, ra, ruda, o sauce:

\begin{tabular}{|c|c|}
\hline$D R A E 1817$ & $D R A E 1822$ \\
\hline $\begin{array}{l}\text { PESO [9]. Instrumento bien conocido, que sirve } \\
\text { para examinar la gravedad y peso de las cosas. } \\
\text { Tiene el fiel en medio de los brazos iguales, y } \\
\text { en los extremos de ellos las balanzas, por cuya } \\
\text { razon le llaman vulgarmente PESO DE CRUZ. }\end{array}$ & $\begin{array}{l}\text { PESO [9]. Instrumento que sirve para examinar la } \\
\text { gravedad y peso de las cosas. Tiene el fiel en } \\
\text { medio de los brazos iguales, y en los extremos } \\
\text { de ellos las balanzas, por cuya razon le llaman } \\
\text { vulgarmente PESO DE CRUZ. }\end{array}$ \\
\hline $\begin{array}{l}\text { PÓLVORA. s. f. Compuesto bien conocido que } \\
\text { se hace de azufre, salitre y carbon, de que } \\
\text { se forman unos granillos negros menudos, } \\
\text { fácilmente inflamables y de gran violencia } \\
\text { por lo mucho que se extiende. }\end{array}$ & $\begin{array}{l}\text { PÓLVORA. s. f. Misto de azufre, salitre y } \\
\text { carbon, de que se forman unos granillos negros } \\
\text { menudos, fácilmente inflamables y de gran } \\
\text { violencia por lo mucho que se extiende. }\end{array}$ \\
\hline $\begin{array}{l}\text { SARAMPIÓN. s. m. Enfermedad conocida, } \\
\text { que comunmente da á los niños, empezando } \\
\text { con unas calenturas ardentísimas, pintándose } \\
\text { todo el cuerpo de unos granos arracimados } \\
\text { menudos y rojos. }\end{array}$ & $\begin{array}{l}\text { SARAMPIÓN. s. m. Enfermedad que } \\
\text { comunmente da á los niños, empezando con } \\
\text { unas calenturas ardentísimas, pintándose todo } \\
\text { el cuerpo de unos granos arracimados menudos } \\
\text { y rojos. }\end{array}$ \\
\hline
\end{tabular}


Esta supresión no se produce de manera sistemática en la edición de 1822 sino que se llevará a cabo en distintas ediciones del siglo XIX. Por ejemplo, en el término maravilla [3] se omitirá en la edición de 1832, en hoz en la de 1843, en ajedrez en la de 1869 y en las voces laurel, judia y tomatera en 1884.

\subsubsection{Supresión de información enciclopédica}

Por último, otra de las intervenciones que se llevaron a cabo en la sexta edición para reducir las definiciones fue la supresión de información enciclopédica, es decir, aquella que no ofrece características distintivas e individuales de la voz que se está definiendo sino explicaciones adicionales. Habitualmente los rasgos semánticos suelen ordenarse de mayor a menor relevancia. Entre estos últimos se hallan los datos enciclopédicos, por lo que es habitual recortar información del final de la definición.

En ocasiones se omiten alusiones culturales o noticias históricas presentes en la quinta edición, las cuales provenían del Diccionario de autoridades ${ }^{28}$, como en la voz aportella$d o$, en la que se eliminan datos precisos de este oficio en el pasado, en cobalto, en cuya definición se señalaba el lugar concreto en el que fue descubierto el mineral, en diaconisa, en la que se ofrecía el atuendo y empleo de dicha mujer, o en era, en la que se suprime la explicación que hacía referencia al momento en el que se dejó de contar por eras en Castilla y se empezó a hacerlo en años. Otros ejemplos son las voces ante [3], creatura, digesto, época, epulón, era cristiana (s. v. era) y fugitivo [2]. Esta tendencia a eliminar datos culturales o información histórica entra en contradicción con la inclusión en el suplemento de la edición de 1822 de la forma compleja corrección gregoriana, la definición de la cual se compone de 15 líneas en las que se explica en qué consistió esta corrección llevada a cabo en el año 1582.

Este tipo de procedimiento es bastante habitual en las voces pertenecientes a la historia natural: plantas, animales y minerales, en cuyas explicaciones es común hallar rasgos descriptivos, puesto que la definición se construye en base a las características de la cosa representada. Como se ha demostrado en el estudio de Gómez de Enterría (2018: cap. 12), en las definiciones de las voces pertenecientes a la historia natural se descarta el método comparativo y se usa un nuevo enfoque en el que se refleja "la influencia de la sistemática linneana"29 (Gómez de Enterría 2018: 293). Como consecuencia de ello, surgen unas definiciones un tanto extensas que no conciertan con el objetivo reductor de la sexta edición. Para intentar acortarlas, se ha observado una tendencia a eliminar en las plantas y minerales algunos usos y funciones de los mismos, así como su empleo en otras disciplinas, especial-

28 La decisión de incluir datos históricos y culturales aparece explicada en el prólogo de la segunda edición del Diccionario de autoridades (1770: prólogo): "En algunas cosas propias y antiguas de España no se contenta la Academia con la definición precisa de las voces, porque no bastaría para darlas á conocer: y por esta razon explica con individualidad lo que fueron en lo pasado Alferez del Rey, Alferez mayor de los Peones de Castilla, Almogavar, Aportellado y otras semejantes". Los datos históricos y culturales que aparecen desde el Diccionario de autoridades en las definiciones de estas voces se reducen en la sexta edición del diccionario académico.

29 Gómez de Enterría (2018: 281) explica que la taxonomía de Linneo, quien clasifica los seres vivos en diferentes niveles jerárquicos, ya se conocía en España desde 1751, "sin embargo, el nuevo sistema no se implantará como método de enseñanza hasta muy avanzada la segunda mitad del siglo". Continua esta autora (Gómez de Enterría 2018: 281) indicando que el retraso en la aceptación de la clasificación linneana "condicionará la revisión de las entradas de ciencias naturales en la quinta edición". 
mente, en farmacia y medicina. En Clavería y Paz (en prensa), se ha puesto de manifiesto que una de las características más notables en la edición de 1817 es la ampliación de las utilidades en los términos que denominan minerales. En algunos de ellos el empleo ya aparecía en ediciones anteriores, aunque en la quinta se acentúa este procedimiento. Teniendo en cuenta los datos cotejados, esta afirmación se puede aplicar también a las plantas. Son ejemplos de ello las definiciones de las voces abrojo, abrótano, almáciga, almagre, ánime, borraja, cardamomo o sauce:

\begin{tabular}{|c|c|}
\hline$D R A E 1817$ & $D R A E 1822$ \\
\hline $\begin{array}{l}\text { ABROJO. s. m. Planta anua, que echa varios } \\
\text { tallos tendidos contra la tierra, y el fruto } \\
\text { redondo y armado de cinco puas en forma de } \\
\text { radios triangulares. Los antiguos usaban del } \\
\text { conocimiento de esta planta para refrescar. }\end{array}$ & $\begin{array}{l}\text { ABROJO. s. m. Planta que echa varios tallos } \\
\text { tendidos por la tierra, y el fruto redondo y } \\
\text { armado de cinco puas en forma de radios } \\
\text { triangulares. }\end{array}$ \\
\hline $\begin{array}{l}\text { ABRÓTANO. s. m. Mata cuyas hojas, que son } \\
\text { muy delgadas y blanquecinas, así como } \\
\text { sus tallos tiernos se emplean en la farmacia } \\
\text { contra las lombrices, y como un antistérico } \\
\text { y aperitivo. }\end{array}$ & $\begin{array}{l}\text { ABRÓTANO. s. m. Mata cuyas hojas son muy } \\
\text { delgadas y blanquecinas, y sus tallos tiernos, } \\
\text { y despide un olor suave. Se suele usar contra } \\
\text { las lombrices. }\end{array}$ \\
\hline $\begin{array}{l}\text { BORRAJA. s. f. Planta anua que crece hasta pie } \\
\text { y medio. Tiene el tallo ramoso, cilíndrico, } \\
\text { hueco y jugoso: las hojas grandes y aovadas, } \\
\text { y las flores de un hermoso color azul, y } \\
\text { dispuestas en racimo. Toda ella esta cubierta } \\
\text { de pelos ásperos y punzantes. En varias } \\
\text { partes la cultivan y comen cocida, y su flor } \\
\text { es una de las que en la medicina se conocen } \\
\text { con el nombre de flores cordiales. }\end{array}$ & $\begin{array}{l}\text { BORRAJA. s. f. Planta anua que crece hasta } \\
\text { pie y medio. Tiene el tallo ramoso, las hojas } \\
\text { grandes y aovadas, y las flores de un hermoso } \\
\text { color azul, y dispuestas en racimo. Toda ella } \\
\text { esta cubierta de pelos ásperos y punzantes. }\end{array}$ \\
\hline
\end{tabular}

Tabla 29.

La información referente a los usos, nueva en la quinta edición, será eliminada en la edición de 1822 acercando la definición a las ediciones anteriores a la de 1817. Es interesante la información suprimida en la voz abrótano, ya que el término antistérico ${ }^{30}$ no se encuentra documentado hasta la duodécima edición en la que aparece registrado como antihistérico, al cual se le asigna la marca de medicina (Med.). Hasta la edición de 1884, la Academia había adoptado un punto de vista más restrictivo en cuanto a la introducción de tecnicismos ( $c f r$. Clavería 2016: 174). En este caso, la eliminación de la información relacionada con el empleo de esta planta puede estar motivada por la ausencia en la nomenclatura del diccionario de la palabra presente en la definición.

Sin embargo, la omisión de las utilidades no se produce de un modo sistemático, ya que en algunas voces se mantienen hasta finales del siglo XIX, como en mechoacán o mejorana. Las definiciones de las plantas no presentan más alteraciones significativas hasta la

30 Si aparece, en cambio, la voz aperitivo, definida como "Med. Se aplica á los remedios que tienen virtud para abrir las vias" (s. v. aperitivo, va). 
duodécima edición, en la que se recuperan algunas propiedades medicinales y de uso. Este es el caso de borraja, en cuya definición se indica que "su flor se emplea como sudorífico" (DRAE 1884: s. v. borraja).

También es frecuente disminuir las definiciones de las palabras que denominan animales, ya sea reescribiendo enteramente la definición (ánsar, erizo, gorrión, gozque) o eliminando información suplementaria (equino o freza) o que no es necesaria para el reconocimiento del animal (anta). En Gómez de Enterría (2018: 296) se ha puesto de manifiesto que en la quinta edición existe un interés por destacar detalles superfluos en las entradas de las voces relacionadas con la zoología. Estos detalles se empezarán a eliminar en la edición de 1822:

\begin{tabular}{|c|c|}
\hline DRAE 1817 & DRAE 1822 \\
\hline $\begin{array}{l}\text { ANTA. s. f. Especie de ciervo mayor que el } \\
\text { comun, y que se diferencia principalmente } \\
\text { de él en que sus cuernos desde el mismo } \\
\text { nacimiento estan divididos como los dedos de } \\
\text { una mano. Su piel es muy dura, y es animal } \\
\text { tan ligero que anda al dia de diez y seis } \\
\text { á veinte leguas. Úsase en la farmacia su } \\
\text { pezuña, que es conocida con el nombre de } \\
\text { Uña de Gran Bestia. }\end{array}$ & $\begin{array}{l}\text { ANTA. s. f. Especie de ciervo mayor que el } \\
\text { comun, y que se diferencia principalmente } \\
\text { de él en que sus cuernos desde el mismo } \\
\text { nacimiento estan divididos como los dedos de } \\
\text { una mano. }\end{array}$ \\
\hline $\begin{array}{l}\text { ERIZO. s. m. Animal cuadrúpedo como de } \\
\text { diez pulgadas de largo, con el dorso y los } \\
\text { lados cubiertos de puas agudas, brunas por } \\
\text { el medio, grises por la punta, y lo demás } \\
\text { del cuerpo de pelo blanquzino y rojizo, la } \\
\text { cabeza pequeña, el hocico afilado y algo } \\
\text { parecido al del cerdo, las orejas anchas, } \\
\text { pequeñas y casi redondas, los ojos chicos, } \\
\text { la cola corta y cinco dedos en cada pie. } \\
\text { Cuando se le persigue se contrae de modo } \\
\text { que forma una bola espinosa por todas } \\
\text { partes. }\end{array}$ & $\begin{array}{l}\text { ERIZO. s. m. Animal cubierto de puas, pequeño } \\
\text { de cuerpo y semejante al puerco. }\end{array}$ \\
\hline
\end{tabular}

Tabla 30.

Como se puede observar en la tabla 30, igual que en las plantas o en algunos minerales, en anta también se ha eliminado la información en la que se indica el empleo de la pezuña de este animal en la farmacia. Por lo que respecta a la definición de la voz erizo, se ha reescrito usando como fuente las ediciones anteriores del diccionario de la Academia en las que la definición es prácticamente la misma que en la edición de 1822: "ERIZO. s. m. Animal cubierto de puas, pequeño de cuerpo y semejante al puerco en figura. Quando le quieren coger se recoge y hace como un ovillo" (DRAE 1780-1803).

En relación a las voces pertenecientes a la historia natural, cabe destacar que en aquellas ubicadas en las primeras letras del alfabeto se elimina de manera sistemática la calificación “indígena de España” y sus variantes, "indígena de los mares de España”, “indígena de algunas partes de España”, etc., como en ajonjera, alacranera, ánsar, alargama, albaldín, 
algazul, amarguera, amormío, anjelote, belesa, borni, borrachuela, entre otras. En las letras restantes la supresión se llevará a cabo en ediciones posteriores a la sexta, como en pájaro carpintero o pájaro diablo, que se elimina en la séptima edición. Por el contrario, la designación "indígena de la India oriental" o "indígena de América" se mantendrá en la sexta edición pero se suprimirá en ediciones posteriores. Son ejemplo de ello las voces pavo, pavo real, patata u ocozol, en las que se elimina en 1832 o vaca marina, en 1869.

\subsection{Norma y estilo}

Entre las modificaciones llevadas a cabo en las definiciones hay una serie de ellas que responden a cuestiones de norma y estilo, puesto que afectan (§ 4.3.1.) al tiempo verbal utilizado en el enunciado definicional, (§ 4.3.2.) al estilo de la redacción y (§ 4.3.3.) a la puntuación de las oraciones.

\subsubsection{Cambios en el tiempo verbal}

Los cambios en el tiempo verbal utilizado en la redacción de las definiciones se pueden deber a distintas cuestiones. En algunos casos, la modificación se realiza para mantener la coherencia de tiempo dentro de una misma oración. Así, por ejemplo, en la definición de la expresión la última sardina de la banasta (s. v. sardina), en la edición de 1817 se conjugaba un verbo en presente (explica) con otro verbo en pasado (buscaba), lo cual se subsanó en la edición siguiente:

\begin{tabular}{|r|r|}
\hline \multicolumn{1}{|c|}{$\boldsymbol{D R} \boldsymbol{A E} \mathbf{1 8 1 7}$} & $\boldsymbol{D R A E} \mathbf{1 8 2 2}$ \\
\hline $\begin{aligned} \text { LA ÚlTIMA SARDINA DE LA BANASTA. Modo de hablar } \\
\text { con que se explica haber llegado a lo último } \\
\text { de las cosas, entre tanto que se buscaba otra ó } \\
\text { de las que se van gastando. }\end{aligned}$ & $\begin{array}{r}\text { con que se explica haber llegado a lo último } \\
\text { de las que se van gastando. }\end{array}$ \\
\hline
\end{tabular}

\section{Tabla 31 .}

Estos cambios también pueden responder a cuestiones de acordar la definición al momento histórico al que esta se refiere, como, por ejemplo, en las voces penitenciado [2], pentecostés o sargento [2]:

\begin{tabular}{|c|c|}
\hline \multicolumn{1}{|c|}{ DRAE 1817 } & \multicolumn{1}{c|}{ DRAE 1822 } \\
\hline $\begin{array}{l}\text { PENITENCIADo [2]. adj. El que es castigado por la } \\
\text { inquisición. }\end{array}$ & $\begin{array}{l}\text { PENITENCIADo [2]. adj. El que era castigado por la } \\
\text { inquisición. }\end{array}$ \\
\hline $\begin{array}{l}\text { PENTECOSTES. s. m. Era una fiesta de los } \\
\text { judíos, instituida en memoria de la ley que }\end{array}$ & $\begin{array}{l}\text { PENTECOSTES. s. m. Fue una fiesta de los } \\
\text { judíos, instituida en memoria de la ley que } \\
\text { Dios les dió en el monte Sinaí, y se celebraba } \\
\text { cincuenta dias despues de la pascua del en el monte Sinaí, y se celebraba } \\
\text { cordero; [...]. }\end{array}$ \\
$\begin{array}{l}\text { cincuenta dias despues de la pascua del } \\
\text { cordero; [...]. }\end{array}$ \\
\hline
\end{tabular}




\begin{tabular}{|c|c|}
\hline $\boldsymbol{D R} \boldsymbol{A E} \mathbf{E 1 7 7}$ & \multicolumn{1}{c|}{$\boldsymbol{D R A E} \mathbf{1 8 2 2}$} \\
\hline $\begin{array}{c}\text { SARGENTo [2]. s. m. El alcalde de corte inmediato } \\
\text { en antigüedad á los cinco que tienen saleta, el } \\
\text { cual debe servir por cualquiera de ellos que } \\
\text { está impedido por enfermedad ó ausencia. }\end{array}$ & $\begin{array}{c}\text { SARGENTO [2]. s. m. El alcalde de corte inmediato } \\
\text { en antigüedad á los cinco que tenian saleta, } \\
\text { el cual debia servir por cualquiera de ellos } \\
\text { que estuviese impedido por enfermedad ó } \\
\text { ausencia. }\end{array}$ \\
\hline
\end{tabular}

Tabla 32.

En la definición de penitenciado [2] se modifica el tiempo verbal del presente al pasado seguramente por referirse a un hecho que ocurría durante la época de la inquisición. En el momento histórico en el que se redactó la edición de 1822 la abolición de la inquisición ya se había aprobado por mayoría absoluta en las Cortes de Cádiz de 1812, aunque no se suprimió definitivamente hasta 1834. En cambio, en la definición de pentecostés se altera el tiempo verbal del pretérito imperfecto al pretérito indefinido, un tiempo más pasado, por referirse a una fiesta que, según el diccionario, se celebraba hace mucho tiempo. Finalmente, en la definición de sargento se modifican todos los verbos de presente a pasado posiblemente por considerar que lo definido ya no era válido para el momento actual del diccionario.

\subsubsection{Cambios en la redacción}

En cuanto a la redacción, se hallan algunas definiciones que experimentan pequeñas modificaciones en el orden de sus componentes. Esos cambios, la mayoría de veces son simplemente estilísticos, como en volver [13], erector, ra, o puesto en el borrico (s. v. borrico).

\begin{tabular}{|c|c|}
\hline \multicolumn{1}{|c|}{$\boldsymbol{D R A E} \mathbf{1 8 1 7}$} & $\boldsymbol{D R A E} \mathbf{1 8 2 2}$ \\
\hline $\begin{array}{c}\text { VOLVER [13]. Hacer mudar el dictámen que se } \\
\text { tenia con persuaciones ó razones. }\end{array}$ & $\begin{array}{c}\text { VOLVER [13]. Hacer con persuasiones ó razones } \\
\text { mudar el dictámen que se tenia. }\end{array}$ \\
\hline
\end{tabular}

Tabla 33.

En cambio, otras veces, pueden responder a una cuestión sintáctica de orden de la oración y de sus complementos, como en gorullo, borra [4], botana o a gran seca gran mojada (s. v. mojada).

\begin{tabular}{|l|l|}
\hline \multicolumn{1}{|c|}{$\boldsymbol{D R} \boldsymbol{A} \boldsymbol{E} \mathbf{1 8 1 7}$} & \multicolumn{1}{c|}{$\boldsymbol{D R \boldsymbol { A } \boldsymbol { E } \mathbf { 1 8 2 2 }}$} \\
\hline $\begin{array}{l}\text { GORULLO. s. m. El bulto que se forma } \\
\text { pequeño y redondo uniéndose y apretándose } \\
\text { casualmente unas con otras las partes que } \\
\text { estaban sueltas, como en la lana, en la masa } \\
\text { \&c. }\end{array}$ & $\begin{array}{l}\text { GORULLO. s. m. El bulto pequeño y redondo } \\
\text { que se forma uniéndose y apretándose } \\
\text { casualmente unas con otras las partes que } \\
\text { estaban sueltas, como en la lana, en la masa } \\
\text { \&c. }\end{array}$ \\
$\begin{array}{l}\text { BORRA [4] Pelo que saca el tundidor del paño con } \\
\text { la tijera. }\end{array}$ & $\begin{array}{l}\text { BORRA [4] Pelo que el tundidor saca del paño con } \\
\text { la tijera. }\end{array}$ \\
\hline
\end{tabular}




\begin{tabular}{|c|c|}
\hline DRAE 1817 & DRAE 1822 \\
\hline $\begin{array}{c}\text { BOTANA. El pedazito de palo redondo que se } \\
\text { pone en los agujeros que se hacen en las botas } \\
\text { ó pellejos de vino para que no se salga. }\end{array}$ & $\begin{array}{c}\text { BOTANA El pedazito redondo de palo que se } \\
\text { pone en los agujeros que se hacen en las botas } \\
\text { ó pellejos de vino para que no se salga. }\end{array}$ \\
\hline
\end{tabular}

Tabla 34 .

Como se puede observar en la tabla 34, en botana el cambio de orden responde a la intención de esclarecer el sentido de la definición, puesto que se especifica que lo que tiene la cualidad de redondo era el pedazito y no el palo.

\subsubsection{Cambios en la puntuación}

La intención de mejorar el estilo de las definiciones algunas veces también se refleja en los cambios de puntuación, como, por ejemplo, en pensar [2], en la que se sustituye una $o$ copulativa por una coma, o en la definición de las voces sarcocola, digresión y fresno, en las que se unen dos oraciones separadas por un punto o por una coma mediante la inclusión de un que relativo:

\begin{tabular}{|c|c|}
\hline \multicolumn{1}{|c|}{ DRAE 1817 } & DRAE 1822 \\
\hline $\begin{array}{c}\text { PENSAR [2]. Reflexionar ó examinar con cuidado } \\
\text { alguna cosa para formar dictamen. }\end{array}$ & $\begin{array}{l}\text { PENSAR [2]. Reflexionar, examinar con cuidado } \\
\text { alguna cosa para formar dictamen. }\end{array}$ \\
\hline $\begin{array}{l}\text { SARCOCOLA, s. f. Farm. Goma de color } \\
\text { amarillo, de sabor amargo, compuesto de } \\
\text { unos granillos esponjosos y correosos. Fluye } \\
\text { de un arbusto de Etiopia. }\end{array}$ & $\begin{array}{l}\text { SARCOCOLA, s. f. Farm. Goma de color } \\
\text { amarillo, de sabor amargo, compuesta de unos } \\
\text { granillos esponjosos y correosos, que fluye de } \\
\text { un arbusto de Etiopia. }\end{array}$ \\
\hline
\end{tabular}

Tabla 35 .

\subsection{Corrección de errores}

Finalmente, debido a la rapidez con la que se confeccionó la edición de 1817, solamente en diecisiete meses (DRAE 1817: prólogo; cfr. Clavería 2018), se generan algunos errores en las definiciones nuevas de 1817 que serán enmendados en 1822. Estos fallos se deben, sobre todo, a cuestiones de concordancia, como en lucero [2], penitencia [4] y tenedero, en las que se evita la cacofonía, o cambios entre la conjunción copulativa y disyuntiva, como en abridor o a ruego ó a su ruego (s. v. ruego).

\begin{tabular}{|c|c|}
\hline \multicolumn{1}{|c|}{ DRAE $\mathbf{1 8 1 7}$} & $\boldsymbol{D R A E} \mathbf{1 8 2 2}$ \\
\hline $\begin{array}{l}\text { TENEDERO. s. m. Náut. Suelo del mar donde } \\
\text { prende y se afirma la ancla. }\end{array}$ & $\begin{array}{c}\text { TENEDERO. s. m. Náut. Suelo del mar donde } \\
\text { prende y se afirma el ancla. }\end{array}$ \\
\hline $\begin{array}{l}\text { PENITENCIA [4]. Cualquiera acto de mortificacion } \\
\text { interior ó exterior. }\end{array}$ & $\begin{array}{l}\text { PENITENCIA [4]. Cualquier acto de mortificacion } \\
\text { interior ó exterior. }\end{array}$ \\
\hline
\end{tabular}




\begin{tabular}{|c|c|}
\hline DRAE 1817 & DRAE 1822 \\
\hline $\begin{array}{c}\text { ABRIDOR. s. m. Prov. de Aragon y Navarra. Lo } \\
\text { mismo que ABRIDERo, árbol o fruta. }\end{array}$ & $\begin{array}{c}\text { ABRIDOR. s. m. Prov. de Aragon y Navarra. Lo } \\
\text { mismo que ABRIDERo, árbol y fruta. }\end{array}$ \\
\hline
\end{tabular}

Tabla 36.

También se han subsanado algunos errores derivados de la reformulación de las definiciones de 1803, como en zapote. En la cuarta edición se indica que las hojas del zapote son "como las del laurel", planta que tiene las hojas "verdes, largas, tiesas, puntiagudas venosas y aromáticas" (DRAE 1817: s. v. laurel). En la siguiente edición se reescribe la definición del vocablo zapote y se señala que sus hojas son "verde claro, acorazonadas, puntiagudas" (DRAE 1817: s. v. zapote). Este error en la forma de las hojas del árbol se subsana en la edición de 1822 .

A diferencia de los casos anteriores, el error en la definición de la voz erizado [2], ejemplificado en la tabla 37, no proviene de la edición anterior sino desde su incorporación en el diccionario en 1791.

\begin{tabular}{|c|c|}
\hline DRAE 1817 & DRAE $\mathbf{1 8 2 2}$ \\
\hline $\begin{array}{l}\text { ERIZADo [2]. adj. Lo que está cubierto de púas ó } \\
\text { espinas, como el puerco \&c. }\end{array}$ & $\begin{array}{c}\text { ERIZADO [2]. adj. Lo que está cubierto de púas ó } \\
\text { espinas, como el espin \&c. }\end{array}$ \\
\hline
\end{tabular}

Tabla 37.

El error es subsanado reemplazando el término puerco por espín, ya que el animal que "está cubierto de puas o espinas" no es el puerco sino el puerco espín.

\section{CONCLUSIÓN}

En la sexta edición del diccionario de la Academia no se pretende hacer una revisión del repertorio basada en la ampliación del lemario sino, más bien, asentada en la corrección y perfeccionamiento de la edición anterior, así como en la disminución del cuerpo de la obra, utilizando para ello tanto la supresión de lemas como la reducción de la parte definitoria de los artículos.

Con esta edición se inicia una importante reestructuración del diccionario usual que tiene como objetivo la disminución del volumen la obra, tanto a nivel macroestructural como microestructural. Este hecho comporta que, por primera vez, el número de lemas que se suprimen sea notablemente mayor que el número de lemas que se incorporan en la nomenclatura. En este sentido, se purga el lemario de voces con un mismo origen, mayoritariamente variantes fónicas, gráficas y morfológicas, en cuya definición la única información que aparece es la remisión a otro término de uso más común. El mayor número de supresiones se corresponde con voces antiguas, hecho que comporta un cambio en su valoración, puesto que hasta la edición de 1803 se procuró incrementar el número de términos anticuados ${ }^{31}$. También se suprimen adverbios terminados en -mente y, en menor medida, participios, diminutivos, aumentativos, verbos irregulares y verbos pronominales.

31 Este cambio ya se había iniciado en la edición anterior a la estudiada ( $D R A E$ 1817). 
En cuanto a las incorporaciones, cabe destacar el hecho de que muchas de ellas pertenecen a grupos que según las directrices del prólogo y de la reglas debían suprimirse, como, por ejemplo, voces arcaicas con marca ant. y que remiten a su equivalente actual.

En la microestructura, se producen cambios sustanciales en la redacción de las definiciones, un tema que preocupó a los académicos desde la redacción del Diccionario de autoridades. En este sentido, en la $6{ }^{\mathrm{a}}$ edición se sigue la revisión iniciada en la edición anterior. Por lo que se refiere a los cambios más notables, la Academia se propone intervenir básicamente en cuatro aspectos de la definición: hacer más clara su redacción, reducir el volumen de las entradas, revisar el estilo y, finalmente, corregir los errores generados por la rápida elaboración de la edición anterior.

En cuanto al propósito de clarificar las definiciones, los académicos se sirven unas veces de añadir información o retocar algunos elementos del contenido $\mathrm{y}$, otras veces, de redactar de nuevo toda o la mayor parte de la definición.

Para la reducción de las definiciones, hecho que responde a la intención economizadora en papel y dinero que desde la edición anterior guiaba a la corporación, los académicos, por un lado, eliminan partes irrelevantes de las definiciones, suprimiendo palabras y expresiones redundantes así como fórmulas definitorias, y, por otro lado, en el caso de las definiciones enciclopédicas, suprimiendo partes del contenido que aportaban informaciones adicionales que no eran imprescindibles para comprender el significado de la voz definida.

Un tercer aspecto de la definición en el que intervienen los académicos es en el de la pulcritud de su redactado, revisando para ello la norma y el estilo utilizado. En este sentido, las intervenciones se centran en tres aspectos: cambios en los tiempos verbales, motivados principalmente para mantener la coherencia de tiempo dentro de la oración o para ajustar la definición al momento histórico al que se refiere y cambios en el orden de los componentes, debidos a matices estilísticos o a cuestiones sintácticas y cambios en la puntuación, también con la intención de mejorar el estilo.

Finalmente, los académicos también intervienen en la corrección de errores, aspecto importante si se tiene en cuenta el poco tiempo en el que se elaboró la edición anterior: diecisiete meses. El mayor número de errores se debe a cuestiones de concordancia o a cambios entre conjunciones.

En definitiva, se trata, pues, de una edición que representa un eslabón más en el camino de la edición del diccionario académico; un eslabón que se fundamenta en la idea de reducir el volumen de la obra para hacerla más económica y manejable, idea que culminó en la edición siguiente. Para ello, en esta edición se lleva a cabo una reflexión sobre el léxico que debe contener el diccionario y se da cuenta del tipo de vocablos que se han de suprimir, aunque luego, en la práctica, la obra presente incoherencias en la aplicación de las reglas expresadas en el prólogo.

\section{REFERENCIAS BIBLIOGRÁFICAS}

Alvar Ezquerra, M. (1983): "Los prólogos del diccionario académico: nomenclatura específica y microestructura", Revista de Filología Española, 63, pp. 205-222.

Azorín, D. (2018): "El léxico con marcación estilística", en G. Clavería y M. Freixas (coords.): El diccionario de la Academia en el siglo XIX: la 5. ${ }^{a}$ edición al microscopio. Madrid: Arco/Libros, pp.427-458. 
Clavería, G. (2016): De vacunar a dictaminar. La lexicografía académica decimonónica y el neologismo. Madrid: Iberoamericana/Vervuert.

Clavería, G. (2018): "La quinta edición del Diccionario de la lengua castellana (1817) de la Real Academia Española al microscopio", en G. Clavería y M. Freixas (coords.): El diccionario de la Academia en el siglo XIX: la 5. ${ }^{a}$ edición al microscopio. Madrid: Arco/Libros, pp.15-56.

Clavería, G. y Freixas, M. (2015): "La quinta edición del Diccionario de la lengua castellana de la Real Academia Española (1817): el aumento de voces", en J. M. a García Martín (ed.), Actas del IX Congreso Internacional de Historia de la Lengua Española. Madrid/ Frankfurt, Iberoamericana/ Vervuert, vol. II, pp.1309-1326.

Clavería, G. y Paz, A. (en prensa): "El discurso científico en la definición lexicográfica académica (DRAE 1817-1852)", en X. A. Álvarez, J. J. García, M. Martí y A. M. Ruiz (eds.): Nuevas perspectivas en la diacronía de las lenguas de especialidad. Alcalá de Henares: Servicio de Publicaciones de la Universidad de Alcalá.

Carriet, E. (2017): "La séptima edición del diccionario académico (DRAE 1832)", Revista de Lexicografia, 23, pp. 39-65.

Freixas, M. (2010): Planta y método del Diccionario de autoridades. Orígenes del método lexicográfico de la Real Academia Española (1713-1739). A Coruña: Universidade de Coruña.

Freixas, M. (2012): "El lexicográfico de la Real Academia Española entre los años 1732-1770: las plantas de la segunda edición del Diccionario de autoridades (tomo I, A-B)", en A. Nomdedeu et. al. (coords.): Avances de lexicografía hispánica. Tarragona: Universitat Rovira i Virgili, vol.I, pp. 301-315.

Freixas, M. (2018): "La definición y la descripción”, en G. Clavería y M. Freixas (coords.): El diccionario de la Academia en el siglo XIX: la 5. ${ }^{a}$ edición al microscopio. Madrid: Arco/Libros, pp. 139-173.

Fries, D. (1989): “Limpia, fija y da esplendor”. La Real Academia Española ante el uso de la lengua (1713-1973). Madrid: SGEL.

Gómez de Enterría, J. (2018): "Las voces de ciencias naturales y áreas afines", en G. Clavería y M. Freixas (coords.): El diccionario de la Academia en el siglo XIX: la 5. ${ }^{a}$ edición al microscopio. Madrid: Arco/Libros, pp. 275-311.

Jiménez Ríos, E. (2001): Variación léxica y diccionario: los arcaísmos en el diccionario de la Academia. Madrid/Frankfurt: Iberoamericana/Vervuert.

Jiménez Ríos, E. (2018): “El léxico con marcación diacrónica", en G. Clavería y M. Freixas (coords.): El diccionario de la Academia en el siglo XIX: la 5. ${ }^{a}$ edición al microscopio. Madrid: Arco/Libros, pp. 399-426.

Matilla Tascón, A. (1982): "Para la historia del Diccionario", Boletín de la Real Academia Española, 62, pp.441-444.

Seco, M. (1987): Estudios de lexicografia española. Madrid: Paraninfo.

Terrón, N. (2019): "Historia de la lengua y lexicografía: el aumento de voces en la 6. a edición del Diccionario de la Academia (1822)". En Arnal, M. ${ }^{a}$ L. et alii (eds.). Actas del X Congreso Internacional de Historia de la Lengua Española. Zaragoza: Institución "Fernando el Católico", vol. II, pp. 1325-1341.

Terrón, N. y Torruella, J. (2019): “La definición sinonímica en la sexta edición del Diccionario de la lengua castellana de la Real Academia Española", Revista de Filología de la Universidad de la Laguna, 39, pp. 307-328.

Zamora Vicente, A. (1999): Historia de la Real Academia Española. Madrid: Espasa. 